\title{
An algorithm based on a new DQM with modified exponential cubic B-splines for solving hyperbolic telegraph equation in $(2+1)$ dimension
}

https://doi.org/10.1515/nleng-2017-0106

Received November 30, 2016; accepted October 12, 2017.

\begin{abstract}
In this paper, a new method modified exponential cubic B-Spline differential quadrature method (mExp-DQM) has been developed for space discretization together with a time integration algorithm for numeric study of $(2+1)$ dimensional hyperbolic telegraph equations. The mExpDQM (i.e., differential quadrature method with modified exponential cubic B-splines as new basis) reduces the problem into an amenable system of ordinary differential equations (ODEs), in time. The time integration SSP-RK54 algorithm has been adopted to solve the resulting system of ODEs. The proposed method is shown stable by computing the eigenvalues of the coefficients matrices while the accuracy of the method is illustrated in terms of $L_{2}$ and $L_{\infty}$ error norms for each problem. A comparison of mExp-DQM solutions with the results of the other numerical methods has been carried out for various space sizes and time step sizes.
\end{abstract}

Keywords: Differential quadrature method, hyperbolic telegraph equation, modified exponential cubic B-splines, mExp-DQM, Thomas algorithm

MSC: 35L04; 35L10; 74Sxx

\section{Introduction}

The hyperbolic partial differential equations have a great attention due to its useful understanding in various physical phenomena of applied sciences and engineering, for instance, hyperbolic partial differential equation models

*Corresponding Author: Brajesh Kumar Singh, Department of Applied Mathematics, Babasaheb Bhimrao Ambedkar University Lucknow-226 025 (UP) India, E-mail: bksingh0584@gmail.com Pramod Kumar, Department of Applied Mathematics, School for Physical Sciences, Babasaheb Bhimrao Ambedkar University Lucknow-226 025 (UP), India, E-mail: bbaupramod@gmail.com fundamental equations in atomic physics [1], vibrations of structures (e.g. buildings, machines and beams).

Consider second order two-space dimensional linear hyperbolic telegraph equation

$$
\begin{aligned}
& \frac{\partial^{2} u(x, y, t)}{\partial t^{2}}+2 \alpha \frac{\partial u(x, y, t)}{\partial t}+\beta^{2} u(x, y, t) \\
& =\frac{\partial^{2} u(x, y, t)}{\partial x^{2}}+\frac{\partial^{2} u(x, y, t)}{\partial y^{2}}+f(x, y, t),(x, y) \in \Omega, t>0,
\end{aligned}
$$

together with the initial conditions

$$
u(x, y, 0)=\phi(x, y), \quad u_{t}(x, y, 0)=\psi(x, y), \quad(x, y) \in \Omega,
$$

and the boundary conditions either of Dirichlet type (3) or Neumann type (4) as follows

$$
\begin{aligned}
& u(0, y, t)=\phi_{1}(y, t), u(1, y, t)=\phi_{2}(y, t), \\
& u(x, 0, t)=\phi_{3}(x, t), u(x, 1, t)=\phi_{4}(x, t) \text { on } \partial \Omega, t>0 \\
& u_{x}(0, y, t)=\psi_{1}(y, t), u_{x}(1, y, t)=\psi_{2}(y, t), \\
& u_{y}(x, 0, t)=\psi_{3}(x, t), u_{y}(x, 1, t)=\psi_{4}(x, t) \text { on } \partial \Omega, t>0
\end{aligned}
$$

where $\psi, \phi, \psi_{i}, \phi_{i}(i=1,2,3,4)$ are known smooth functions.

where $\partial \Omega$ is the boundary of the computational domain $\Omega=[0,1]^{2}, \alpha>0, \beta$ are arbitrary constants. Eq. (1) with $\beta=0$ is a damped wave equation while for $\beta>0$ it becomes telegraph equation which is more convenient than diffusion equation in modeling reaction-diffusion for such branches of sciences [2], and mostly used in wave propagation of electric signals in a cable transmission line [3], etc.

Bellman et al. [15] developed "differential quadrature method (DQM)" for numeric study of partial differential equations (PDEs). After seminal work of Bellman et al., Quan and Chang $[16,17]$, the DQM has been employed with different base functions such as polynomial based DQM (PDQM) [7], cubic B-spline DQM [18, 19], MCB-DQM $[9,20,22,23]$, DQM based on fourier expansion and Harmonic function [24], sinc DQM [25], generalized DQM [26], 
quartic B-spline based DQM [27, 28], Quartic and quintic B-spline methods $[29,30]$ and exponential cubic B-spline DQM [31].

In the past years, various techniques have been developed for numerical study of PDEs [6, 7, 12]. 2D telegraph equation has been studied numerically via. Taylor matrix method [5], meshless local weak-strong (MLWS) method and meshless local Petrov-Galerkin (MLPG) method [2], higher order implicit collocation method [6], PDQM [7, 8], modified cubic B-spline DQM (MCB-DQM) [9], an alternating direction implicit scheme [10], hybrid method by Dehghan and Salehi [11], modified extended cubic B-spline DQM (mECDQ) [12], compact finite difference scheme with accuracy of order four in both space and time [13] and a meshless scheme with radial basis functions [14].

In this paper our aim is to proposed modified exponential cubic-B-spline differential quadrature method (mExp-DQM) for hyperbolic PDEs. The mExp-DQM is used to convert the initial- boundary value system of the telegraph equation into a initial value system of ODEs, in time. Among various time integration algorithm SSP-RK54 algorithm [32] is adopted to solve the resulting system of ODEs.

The rest of the paper is organized into five more sections. Section 2 deals with the description of mExp-DQM. Section 3 presents the procedure for the implementation of mExp-DQM for the problem (1) with the initial conditions (2) and the boundary conditions (3) or (4). The stability analysis of mExp-DQM is studied in Section 4. The main goal, the numeric study of six test problems to establish the accuracy of the proposed method is carried out in terms of the relative error $\left(R_{e}\right), L_{2}$ and $L_{\infty}$ error norms in Section 5. Finally, Section 6 concludes the paper with reference to critical analysis and research perspectives.

\section{Description of mExp-DQM}

The DQM is an approximation to derivatives of a function is the weighted linear sum of the functional values at certain grid points[15], where the weighting coefficients depend on grids only [26], and so, a uniform partition $P[\Omega]=$ $\left\{\left(x_{i}, y_{j}\right) \in \Omega: h_{x}=x_{i+1}-x_{i}, h_{y}=y_{j+1}-y_{j}, i \in \Delta_{x}, j \in \Delta_{y}\right\}$, of the domain $\Omega=\left\{(x, y) \in R^{2}: 0 \leq x, y \leq 1\right\}$ of the problem is distributed with the following grid points:

$$
\begin{aligned}
& 0=x_{1}<x_{2}<\ldots<x_{i}<\ldots<x_{N_{x}-1}<x_{N_{x}}=1, \\
& 0=y_{1}<y_{2}<\ldots<y_{j}<\ldots<y_{N_{y}-1}<y_{N_{y}}=1,
\end{aligned}
$$

where $\Delta_{x}=\left\{1,2, \ldots, N_{x}\right\}, \Delta_{y}=\left\{1,2, \ldots, N_{y}\right\}$, and $h_{x}=$ $\frac{1}{N_{x}-1}$ and $h_{y}=\frac{1}{N_{y}-1}$ are the discretization steps in both $x$ and $y$ directions, respectively.
Let $\left(x_{i}, y_{j}\right)$ be the generic grid point and

$$
u_{i j} \equiv u_{i j}(t) \equiv u\left(x_{i}, y_{j}, t\right), i \in \Delta_{x}, j \in \Delta_{y} .
$$

The approximation for $r$-th order derivative of $u(x, y, t)$, for $r \in\{1,2\}$, with respect to $x, y$ at $\left(x_{i}, y_{j}\right)$ for $i \in \Delta_{x}, j \in \Delta_{y}$ is given by

$$
\frac{\partial^{r} u_{i j}}{\partial x^{r}}=\sum_{\ell=1}^{N_{x}} a_{i \ell}^{(r)} u_{\ell j}, \quad i \in \Delta_{x} ; \quad \frac{\partial^{r} u_{i j}}{\partial y^{r}}=\sum_{\ell=1}^{N_{y}} b_{j \ell}^{(r)} u_{i \ell}, \quad j \in \Delta_{y},
$$

where time dependent unknown quantities $a_{i \ell}^{(r)}$ and $b_{j \ell}^{(r)}$ are called weighting functions of the $r$ th-order derivative, which are computed using a set of base functions.

The exponential cubic B-splines function $\zeta_{i}=\zeta_{i}(x)$ at node $i$ in $x$ direction, reads [31,33]:

$$
\begin{aligned}
& \zeta_{i}= \\
& \frac{1}{h_{x}^{3}}\left\{\begin{array}{c}
b_{2}\left\{\left(x_{i-2}-x\right)-\frac{1}{p} \sinh \left(p\left(x_{i-2}-x\right)\right)\right\} \\
x \in\left[x_{i-2}, x_{i-1}\right) \\
a_{1}+b_{1}\left(x_{i}-x\right)+c_{1} \exp \left(p\left(x_{i}-x\right)\right)+d_{1} \exp \left(p\left(x_{i}-x\right)\right) \\
x \in\left[x_{i-1}, x_{i}\right) \\
a_{1}+b_{1}\left(x-x_{i}\right)+c_{1} \exp \left(p\left(x-x_{i}\right)\right)+d_{1} \exp \left(p\left(x-x_{i}\right)\right), \\
x \in\left[x_{i}, x_{i+1}\right) \\
b_{2}\left\{\left(x-x_{i+2}\right)-\frac{1}{p} \sinh \left(p\left(x-x_{i+2}\right)\right)\right\} \\
x \in\left[x_{i+1}, x_{i+2}\right) \\
0, \quad \\
\text { otherwise }
\end{array}\right.
\end{aligned}
$$

where

$$
\begin{aligned}
& a_{1}=\frac{p c h_{x}}{p c h_{x}-s} ; b_{1}=\frac{p}{2}\left(\frac{s^{2}-c(1-c)}{\left(p c h_{x}-s\right)(1-c)}\right), \\
& b_{2}=\frac{p}{2\left(p c h_{x}-s\right)}, c=\cosh \left(p h_{x}\right), s=\sinh \left(p h_{x}\right), \\
& c_{1}=\frac{1}{4}\left\{\frac{\exp \left(-p h_{x}\right)(1-c)+s\left(\exp \left(-p h_{x}\right)-1\right)}{\left(p c h_{x}-s\right)(1-c)}\right\}, \\
& d_{1}=\frac{1}{4}\left\{\frac{\exp \left(p h_{x}\right)(c-1)+s\left(\exp \left(p h_{x}\right)-1\right)}{\left(p c h_{x}-s\right)(1-c)}\right\} .
\end{aligned}
$$

The set $\left\{\zeta_{0}, \zeta_{1}, \zeta_{2}, \ldots, \zeta_{N_{x}}, \zeta_{N_{x}+1}\right\}$ forms a basis over the interval $[a, b]$. The values of $\zeta_{i}$ and its first and second derivatives in the grid point $x_{j}$, denoted by $\zeta_{i j}:=\zeta_{i}\left(x_{j}\right)$, $\zeta_{i j}^{\prime}:=\zeta_{i}^{\prime}\left(x_{j}\right)$ and $\zeta_{i j}^{\prime \prime}:=\zeta_{i}^{\prime \prime}\left(x_{j}\right)$, respectively, read:

$$
\begin{gathered}
\zeta_{i j}= \begin{cases}1, & \text { if } i-j=0, \\
\frac{s-p h}{2\left(p c h_{x}-s\right)}, & \text { if } i-j= \pm 1, \\
0, & \text { otherwise. }\end{cases} \\
\zeta_{i j}^{\prime}= \begin{cases}\frac{-p(1-c)}{2\left(p c h_{x}-s\right)}, & \text { if } i-j=1, \\
\frac{p(1-c)}{2\left(p c h_{x}-s\right)}, & \text { if } j-i=1, \\
0, & \text { otherwise. }\end{cases}
\end{gathered}
$$




$$
\zeta_{i j}^{\prime \prime}= \begin{cases}\frac{-p^{2} s}{\left(p c h_{x}-s\right)}, & \text { if } i-j=0, \\ \frac{p^{2} s}{2\left(p c h_{x}-s\right)}, & \text { if } i-j= \pm 1, \\ 0 & \text { otherwise. }\end{cases}
$$

Analogous to $[20,23]$, modified exponential cubic Bsplines base functions are obtained by modifying exponential cubic B-splines (6) as follows:

$$
\left\{\begin{array}{l}
\psi_{1}(x)=\zeta_{1}(x)+2 \zeta_{0}(x) \\
\psi_{2}(x)=\zeta_{2}(x)-\zeta_{0}(x) \\
\vdots \\
\psi_{j}(x)=\zeta_{j}(x), \text { for } j=3,4, \ldots, N_{x}-2 \\
\vdots \\
\psi_{N_{x}-1}(x)=\zeta_{N_{x}-1}(x)-\zeta_{N_{x}+1}(x) \\
\psi_{N_{x}}(x)=\zeta_{N_{x}}(x)+2 \zeta_{N_{x}+1}(x) .
\end{array}\right.
$$

The set $\left\{\psi_{1}, \psi_{2}, \ldots, \psi_{N_{x}}\right\}$ forms a basis over $[a, b]$ in direction of $x$. Analogously procedure is followed for $y$ direction.

\subsection{The evaluation of the weighting coefficients $a_{i j}^{(r)}$ and $b_{i j}^{(r)}(r=1,2)$}

In order to evaluate the weighting coefficients $a_{i p}^{(1)}$ of first order partial derivative in Eq. (5), the modified exponential cubic B-spline $\psi_{p}(x), p \in \Delta_{x}$ in DQ method are used as set of base functions. Write $\psi_{p i}^{\prime}:=\psi_{p}^{\prime}\left(x_{i}\right)$ and $\psi_{p \ell}:=\psi_{p}\left(x_{\ell}\right)$. In mExp-DQM, the procedure for computing the approximate values of first-order derivatives are as follows

$$
\psi_{p i}^{\prime}=\sum_{\ell=1}^{N_{x}} a_{i \ell}^{(1)} \psi_{p \ell}, \quad p, i \in \Delta_{x} .
$$

Setting $\Psi=\left[\psi_{p \ell}\right], A=\left[a_{i \ell}^{(1)}\right]$ (the unknown weighting coefficient matrix) and $\Psi^{\prime}=\left[\psi_{p i}^{\prime}\right]$, then Eq. (9) can be rewritten as the following system of linear equations:

$$
\Psi A^{T}=\Psi^{\prime} .
$$

Let $\omega=\frac{p(1-c) h_{x}}{p c h_{x}-s}$ and $\theta=\frac{s-p h_{x}}{2\left(p c h_{x}-s\right)}$, then matrix $\Psi$ of order $N_{X}$ can be obtained from (7) and (8):

$$
\Psi=\left[\begin{array}{ccccccc}
\omega & \theta & & & & & \\
0 & 1 & \theta & & & & \\
& \theta & 1 & \theta & & & \\
& & \ddots & \ddots & \ddots & & \\
& & & \theta & 1 & \theta & \\
& & & & \theta & 1 & 0 \\
& & & & & \theta & \omega
\end{array}\right]
$$

and in particular the columns of the matrix $\Psi^{\prime}$ read:

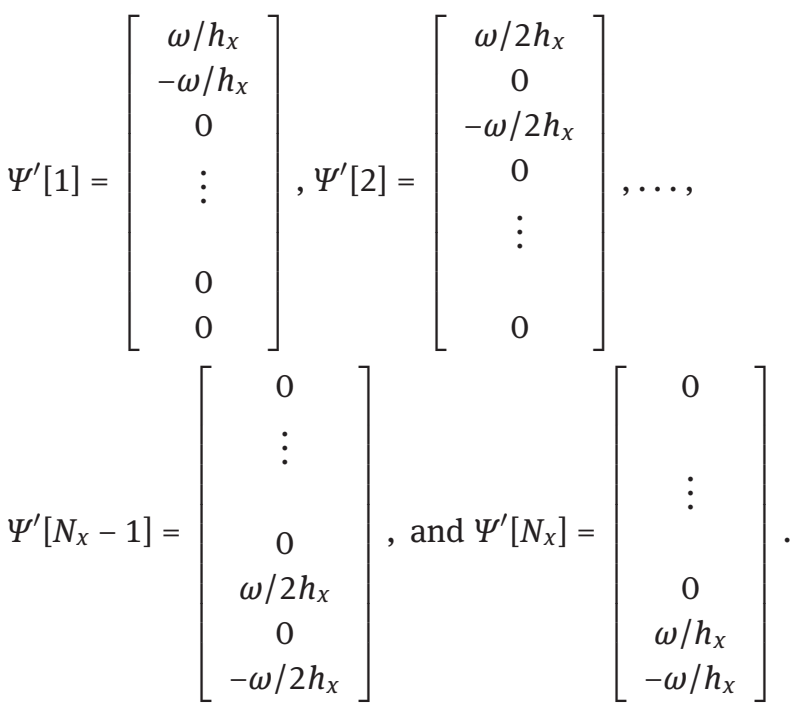

It is worth to remark that the exponential cubic B-splines are modified in order to have a diagonally dominant coefficient matrix $\Psi$, see Eq. (10). To calculate the weighting coefficients, Thomas Algorithm has been employed in system (10). Analogously, the weighting coefficients $b_{i \ell}^{(1)}$ can be computed by considering the grids in the direction of $y$.

In similar manner, the weighting coefficients $a_{i p}^{(r)}$ and $b_{i p}^{(r)}$, for $r \geq 2$, can be calculated using the weighting functions in quadrature formula for second order derivative on the given basis functions. But, in the present paper, we prefer the following recursive formulae [26]:

$$
\left\{\begin{array}{l}
a_{i j}^{(r)}=r\left(a_{i j}^{(1)} a_{i i}^{(r-1)}-\frac{a_{i j}^{(r-1)}}{x_{i}-x_{j}}\right), i \neq j: i, j \in \Delta_{x}, \\
a_{i i}^{(r)}=-\sum_{i=1, i \neq j}^{N_{x}} a_{i j}^{(r)}, i=j: i, j \in \Delta_{x} . \\
b_{i j}^{(r)}=r\left(b_{i j}^{(1)} b_{i i}^{(r-1)}-\frac{b_{i j}^{(r-1)}}{y_{i}-y_{j}}\right), i \neq j: i, j \in \Delta_{y} \\
b_{i i}^{(r)}=-\sum_{i=1, i \neq j}^{N_{y}} b_{i j}^{(r)}, i=j: i, j \in \Delta_{y} .
\end{array}\right.
$$

\section{The mExp-DQM for the telegraph equation}

First, we set $u_{t}=v$ and thus $u_{t t}=v_{t}$. Keeping all above in mind, telegraph equation (1) with the initial condition 
reduces to

$$
\left\{\begin{aligned}
\frac{\partial u(x, y, t)}{\partial t}= & v(x, y, t), \\
\frac{\partial v(x, y, t)}{\partial t}= & -2 \alpha v(x, y, t)-\beta^{2} u(x, y, t)+\frac{\partial^{2} u(x, y, t)}{\partial x^{2}} \\
& +\frac{\partial^{2} u(x, y, t)}{\partial y^{2}}+f(x, y, t),(x, y) \in \Omega, t>0 \\
u(x, y, 0)= & \phi(x, y), \\
v(x, y, 0)= & \psi(x, y), \quad(x, y) \in \Omega .
\end{aligned}\right.
$$

Set $f\left(x_{i}, y_{j}, t\right)=f_{i j}$. mExp-DQM converts Equation (12) to

$$
\left\{\begin{array}{l}
\frac{\partial u_{i j}}{\partial t}=v_{i j}, \\
\frac{\partial v_{i j}}{\partial t}=\sum_{\ell=1}^{N_{x}} a_{i \ell}^{(2)} u_{\ell j}+\sum_{\ell=1}^{N_{y}} b_{j \ell}^{(2)} u_{i \ell}-2 \alpha v_{i j}-\beta^{2} u_{i j}+f_{i j}, \\
u_{i j}(t=0)=\phi_{i j}, \quad v_{i j}(t=0)=\psi_{i j}, \quad i \in \Delta_{x}, j \in \Delta_{y} .
\end{array}\right.
$$

No further simplification is required whenever the boundary conditions are of Dirichlet type. The solution on the boundaries can be read directly from the conditions (3) as:

$\left.\begin{array}{l}u_{1 j}=\phi_{1}\left(y_{j}, t\right)=\phi_{1}(j), u_{N_{x} j}=\phi_{2}\left(y_{j}, t\right)=\phi_{2}(j), j \in \Delta_{y}, \\ u_{i 1}=\phi_{3}\left(x_{i}, t\right)=\phi_{3}(i), u_{i N_{y}}=\phi_{4}\left(x_{i}, t\right)=\phi_{4}(i), i \in \Delta_{x},\end{array}\right\} t \geq 0$.

On the other hand if the boundary conditions are of Neumann or mixed type, further simplification is required. The procedure to find solutions at the boundary is discussed in $[9,34]$, in detail. The mExp-DQM on the boundaries yields a system of linear equations. The solutions at the boundaries are obtained by solving these resulting system of linear equations as follows:

The solution for $u_{1 j}, u_{N_{x} j}$ is obtained from Eq. (5) with $r=1$ and conditions (4) at $x=0$ and $x=1$ as

$$
\begin{aligned}
& u_{1 j}=\frac{S_{1}(j) a_{N_{x} N_{x}}^{(1)}-S_{2}(j) a_{1 N_{x}}^{(1)}}{a_{11}^{(1)} a_{N_{x} N_{x}}^{(1)}-a_{N_{x} 1}^{(1)} a_{1 N_{x}}^{(1)}} \\
& u_{N_{x} j}=\frac{S_{2}(j) a_{11}^{(1)}-S_{1}(j) a_{N_{x} 1}^{(1)}}{a_{11}^{(1)} a_{N_{x} N_{x}}^{(1)}-a_{N_{x} 1}^{(1)} a_{1 N_{x}}^{(1)}}, \quad j \in \Delta_{y},
\end{aligned}
$$

where $S_{1}(j)=\psi_{1}(j)-\sum_{\ell=2}^{N_{x}-1} a_{1 \ell}^{(1)} u_{\ell j}$ and $S_{2}(j)=\psi_{2}(j)-$ $\sum_{\ell=2}^{N_{x}-1} a_{N_{x} \ell}^{(1)} u_{\ell j}$ and the solutions for the boundary values $u_{i 1}$ and $u_{i N_{y}}$ are obtained from Eq. (5) with $r=1$ and the conditions (4) at $y=0$ and $y=1$ as

$$
\begin{aligned}
& u_{i 1}=\frac{S_{3}(i) b_{N_{y} N_{y}}^{(1)}-S_{4}(i) b_{1 N_{y}}^{(1)}}{b_{11}^{(1)} b_{N_{y} N_{y}}^{(1)}-b_{N_{y} 1}^{(1)} b_{1 N_{y}}^{(1)}}, \\
& u_{i N_{y}}=\frac{S_{4}(i) b_{11}^{(1)}-S_{3}(i) b_{N_{y} 1}^{(1)}}{b_{11}^{(1)} b_{N_{y} N_{y}}^{(1)}-b_{N_{y} 1}^{(1)} b_{1 N_{y}}^{(1)}},
\end{aligned}
$$

where $S_{3}(i)=\psi_{3}(i)-\sum_{\ell=2}^{N_{y}-1} b_{1 \ell}^{(1)} u_{i \ell}$ and $S_{4}(i)=\psi_{4}(i)-$ $\sum_{\ell=2}^{N_{y}-1} b_{N_{y} \ell}^{(1)} u_{i \ell}$.

Once the solutions $u_{1 j}, u_{N_{x} j}, u_{i 1}$ and $u_{i N_{y}}$ on boundary are obtained from either boundary condition (Dirichlet type (3) or Neumann type (4)), Eq. (13) can be rewritten as follows:

$$
\left\{\begin{array}{l}
\frac{\partial u_{i j}}{\partial t}=v_{i j}, \\
\frac{\partial v_{i j}}{\partial t}=\sum_{\ell=2}^{N_{x}-1} a_{i \ell}^{(2)} u_{\ell j}+\sum_{\ell=2}^{N_{y}-1} b_{j \ell}^{(2)} u_{i \ell}-2 \alpha v_{i j}-\beta^{2} u_{i j}+K_{i j}, \\
u_{i j}(t=0)=\phi_{i j}, \quad v_{i j}(t=0)=\psi_{i j},
\end{array}\right.
$$

where $2 \leq i \leq N_{x}-1,2 \leq j \leq N_{y}-1$ and

$$
K_{i j}=f_{i j}+a_{i 1}^{(2)} u_{1 j}+a_{i N_{x}}^{(2)} u_{N_{x} j}+b_{j 1}^{(2)} u_{i 1}+b_{j N_{y}}^{(2)} u_{i N_{y}} .
$$

The initial valued system (17) can be solved by using various existing time integration schemes. The SSP-RK algorithm allows low storage and large region of absolute property [32]. In what follows, SSP-RK54 algorithm, strongly stable for nonlinear hyperbolic differential equations, has been adopted.

$$
\begin{aligned}
u^{(1)} & =u^{m}+0.391752226571890 \triangle t L\left(u^{m}\right) \\
u^{(2)} & =0.444370493651235 v^{m} \\
& +0.555629506348765 u^{(1)} \\
& +0.368410593050371 \triangle t L\left(u^{(1)}\right) \\
u^{(3)} & =0.620101851488403 u^{m} \\
& +0.379898148511597 u^{(2)} \\
& +0.251891774271694 \triangle t L\left(u^{(2)}\right) \\
u^{(4)} & =0.178079954393132 u^{m} \\
& +0.821920045606868 u^{(3)} \\
& +0.544974750228521 \triangle t L\left(u^{(3)}\right) \\
u^{m+1} & =0.517231671970585 u^{(2)} \\
& +0.096059710526147 u^{(3)} \\
& +0.063692468666290 \triangle t L\left(u^{(3)}\right) \\
& +0.386708617503269 u^{(4)} \\
& +0.226007483236906 \triangle t L\left(u^{(4)}\right)
\end{aligned}
$$
醇

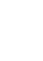


where

$\begin{aligned} \text { a) } & A=\left[\begin{array}{cc}O & I \\ B & -2 \alpha I\end{array}\right], \quad G=\left[\begin{array}{c}O_{1} \\ K\end{array}\right], U= \\ & {\left[\begin{array}{l}u \\ v\end{array}\right] \text {, and } U_{0}=\left[\begin{array}{l}\phi \\ \psi\end{array}\right] }\end{aligned}$

b) $\quad O$ and $O_{1}$ are null matrices;

c) $I$ is the identity matrix of order $\left(N_{x}-2\right)\left(N_{y}-2\right)$;

d) $U=(u, v)^{T}: u=\left(u_{22}, u_{23}, \ldots, u_{2\left(N_{y}-1\right)}, u_{32}\right.$, $\left.u_{33}, \ldots, u_{3\left(N_{y}-1\right)}, \ldots, u_{\left(N_{x}-1\right) 2}, \ldots, u_{\left(N_{x}-1\right)\left(N_{y}-1\right)}\right)$, $v=\left(v_{22}, v_{23}, \ldots, v_{2\left(N_{y}-1\right)}, v_{32}, v_{33}, \ldots, v_{3\left(N_{y}-1\right)}\right.$, $\left.\ldots, v_{\left(N_{x}-1\right) 2}, \ldots, v_{\left(N_{x}-1\right)\left(N_{y}-1\right)}\right)$.

e) $\quad K=\left(K_{22}, K_{23}, \ldots, K_{2\left(N_{y}-1\right)}, K_{32}, \ldots, K_{3\left(N_{y}-1\right)}, \ldots\right.$ $K_{\left(N_{x}-1\right) 2}, \ldots K_{\left(N_{x}-1\right)\left(N_{y}-1\right)}$, where $K_{i j}$, for $i \in \Delta_{x}, j \in$ $\Delta_{y}$ is calculated from Eq. (18).

f) $B=-\beta^{2} I+B_{x}+B_{y}$, where $B_{x}$ and $B_{y}$ are the following matrices (of order $\left(N_{x}-2\right)\left(N_{y}-2\right)$ ) of the weighting coefficients $a_{i j}^{(2)}$ and $b_{i j}^{(2)}$ :

$$
\begin{gathered}
B_{x}=\left[\begin{array}{cccc}
a_{22}^{(2)} I_{x} & a_{23}^{(2)} I_{x} & \ldots & a_{2\left(N_{x}-1\right)}^{(2)} I_{x} \\
a_{32}^{(2)} I_{x} & a_{33}^{(2)} I_{x} & \ldots & a_{3\left(N_{x}-1\right)}^{(2)} I_{x} \\
\vdots & \vdots & \ddots & \vdots \\
a_{\left(N_{x}-1\right) 2}^{(2)} I_{x} & a_{\left(N_{x}-2\right) 3}^{(2)} I_{x} & \ldots & a_{\left(N_{x}-1\right)\left(N_{x}-1\right)}^{(2)} I_{x}
\end{array}\right], \\
B_{y}=\left[\begin{array}{cccc}
M_{y} & O_{y} & \ldots & O_{y} \\
O_{y} & M_{y} & \ldots & O_{y} \\
\vdots & \vdots & \ddots & \vdots \\
O_{y} & O_{y} & \ldots & M_{y}
\end{array}\right],
\end{gathered}
$$

where identity matrix, $I_{x}$, and null matrix, $O_{y}$, both are of order $\left(N_{y}-2\right)$ and

$$
M_{y}=\left[\begin{array}{cccc}
b_{22}^{(2)} & b_{23}^{(2)} & \cdots & b_{2\left(N_{y}-1\right)}^{(2)} \\
b_{32}^{(2)} & b_{33}^{(2)} & \cdots & b_{3\left(N_{y}-1\right)}^{(2)} \\
\vdots & \vdots & \ddots & \vdots \\
b_{\left(N_{y}-1\right) 2}^{(2)} & b_{\left(N_{y}-1\right) 3}^{(2)} & \cdots & b_{\left(N_{y}-1\right)\left(N_{y}-1\right)}^{(2)}
\end{array}\right] .
$$

It is worth mentioning that the stability of mExp-DQM for equation (1) depends upon the stability of system (19) and the proposed method for temporal discretization may not converge to the exact solution whenever system (19) is unstable. The stability of system (19) depends upon the eigenvalues of the coefficient matrix $A$ [35]. In fact, the stability region is the set $\mathcal{S}=\left\{z \in C:|R(z)| \leq 1, z=\lambda_{A} \triangle t\right\}$, where $R\left(\right.$.) is the stability function, $\lambda_{A} \rightarrow$ eigenvalue of the coefficient matrix $A$. The stability region $\mathcal{S}$ for SSP-RK54 algorithm is depicted in Fig 1, see [36, Fig. 5], which confirm that the sufficient condition for the stability of system (19) is that $\lambda_{A} \triangle t \in \mathcal{S}$ for all $\lambda_{A}$, i.e., the real part of each eigenvalue is necessarily either zero or negative.
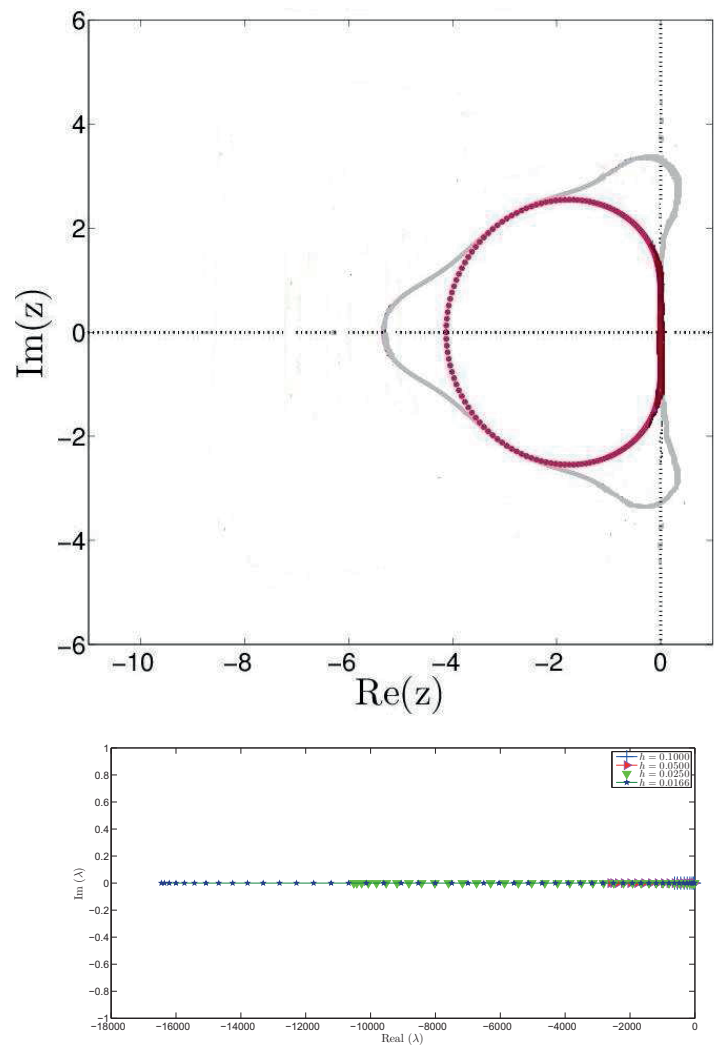

Fig. 1: Stability region for SSP-RK54 algorithm (left) and eigenvalues of $B_{x}+B_{y}$ for different grid sizes $h=0.1,0.01,0.025,0.016$

Let $\lambda_{A}$ be an eigenvalue associated with eigenvector $\left(X_{1}, X_{2}\right)^{T}$, where each component is a vector of order $\left(N_{X}-\right.$ 2) $\left(N_{y}-2\right)$, then Eq. (19) can be re-written as

$$
A\left[\begin{array}{l}
X_{1} \\
X_{2}
\end{array}\right]=\left[\begin{array}{cc}
O & I \\
B & -2 \alpha I
\end{array}\right]\left[\begin{array}{l}
X_{1} \\
X_{2}
\end{array}\right]=\lambda_{A}\left[\begin{array}{l}
X_{1} \\
X_{2}
\end{array}\right],
$$

which yields

$$
B X_{1}=\lambda_{A}\left(\lambda_{A}+2 \alpha\right) X_{1} \text {. }
$$

Eq. (22) implies that eigenvalue $\lambda_{B}$ of $B$ is given by $\lambda_{B}=$ $\lambda_{A}\left(\lambda_{A}+2 \alpha\right)$, where $B=-\beta^{2} I+B_{x}+B_{y}$.

The sufficient condition for the stability of system (19) is that the real part $\operatorname{Re}\left(\lambda_{A}\right)$ for each eigenvalue $\lambda_{A}$ of $A$ is either zero or negative, i.e., $\operatorname{Re}\left(\lambda_{A}\right) \leq 0$. Fig. 1 shows that computed eigenvalue $\lambda$ of $B_{x}+B_{y}$ for $p=1$ with different grid sizes $\left(h_{x}=h_{y}=h=0.1,0.05,0.025,0.016\right)$ are real and negative, and so, each eigenvalue $\lambda_{B}=-\beta^{2}+\lambda$ of $B$ is real and negative, i.e.,

$$
\operatorname{Re}\left(\lambda_{B}\right) \leq 0 \text { and } \operatorname{Im}\left(\lambda_{B}\right)=0,
$$

where $\operatorname{Re}(z)=$ real part of $z, \operatorname{Im}(z)=$ imaginary part of $z$.

Setting $\lambda_{A}=x+\iota y$, and so, $\lambda_{B}=x^{2}-y^{2}+2 \alpha x+2 \iota(x+\alpha) y$, then Eq. (23) yields

$$
x^{2}-y^{2}+2 \alpha x<0 \quad \text { and }(x+\alpha) y=0 .
$$


The above equations are hold simultaneously only when either $x=-\alpha$ or $(x+\alpha)^{2}<\alpha^{2}$ implying that $\operatorname{Re}\left(\lambda_{A}\right)<0$ for each $\alpha>0$.

\subsection{Error estimate and rate of convergence}

Lemma 4.1. $[21,37]$ If the function $u \in C^{4}[a, b]$ such that

$$
u(x)=\sum_{j=1}^{N_{x}} \phi_{j}(x) u\left(x_{j}\right)+E(x),
$$

where $E(x)$ error term and $\phi_{j}(x)$ is any cubic $B$-spline function, then for any partition of $[a, b]$ with uniform grids distribution

i) $|E(x)|_{\infty} \leq \frac{5}{384} h_{x}^{4} M(u) ;$ ii) $\left|E^{(1)}(x)\right|_{\infty} \quad \leq$ $\frac{\sqrt{3}+9}{216} h_{x}^{3} M(u) ;$ iii $)\left|E^{(2)}(x)\right|_{\infty} \leq \frac{5}{12} h_{x}^{2} M(u)$.

where $M(u)=\max _{a \leq x \leq b}\left|u^{4}(x)\right|$. Analogous results in the direction of $y$.

On setting $a_{i j}^{(2)}=\left.\frac{d^{2} \psi_{j}(x)}{d x^{2}}\right|_{x=x_{i}}, b_{j k}^{(2)}=\left.\frac{d^{2} \psi_{k}(y)}{d y^{2}}\right|_{y=y_{j}}$, then for $u \in C^{4}(\Omega, \Omega)$ Lemma 4.1 yields the following

$$
\begin{aligned}
& \left|\frac{\partial^{2} u_{i j}}{\partial x^{2}}-\sum_{k=1}^{N_{x}} a_{i k}^{(2)} u_{k j}\right| \equiv O\left(h_{x}^{2}\right), \\
& \text { and }\left|\frac{\partial^{2} u_{i j}}{\partial y^{2}}-\sum_{k=1}^{N_{y}} b_{j k}^{(2)} u_{i k}\right| \equiv O\left(h_{y}^{2}\right),
\end{aligned}
$$

Hence, Eq. (17) reduces to

$$
\left|\frac{\partial^{2} u_{i j}}{\partial t^{2}}+2 \alpha \frac{\partial u_{i j}}{\partial t}-L\left(u_{i j}\right)\right| \equiv O\left(h^{2}\right) .
$$

where $h=\max \left\{h_{x}, h_{y}\right\}$ and $L\left(u_{i j}\right)=\sum_{\ell=2}^{N_{x}-1} a_{i \ell}^{(2)} u_{\ell j}+$ $\sum_{\ell=2}^{N_{y}-1} b_{j \ell}^{(2)} u_{i \ell}-\beta^{2} u_{i j}+K_{i j}$. This shows that the order of convergence of the mExp-DQM for the telegraph equation is quadratic, which is confirmed numerically from Table 1. amples.

$$
\begin{aligned}
& L_{2}=\left(h \sum_{j=1}^{N}\left[u_{j}^{\text {exact }}-u_{j}^{\star}\right]^{2}\right)^{1 / 2}, L_{\infty}=\max _{j=1}^{N}\left|u_{j}^{\text {exact }}-u_{j}^{\star}\right|, \\
& \text { and } R_{e}=\left(\frac{\sum_{k=1}^{N}\left(u_{k}^{\text {exact }}-u_{k}^{\star}\right)^{2}}{\sum_{k=1}^{N} u_{k}^{2}}\right)^{1 / 2} .
\end{aligned}
$$

where $u_{j}^{\star}$ represent the numerical solution at node $j$. Throughout this section, equal grid size is considered in each direction, i.e., $h_{x}=h_{y}=h$.

Example 5.1. Consider telegraph equation (1) with $f(x, y, t)=\left(-2 \alpha+\beta^{2}-1\right) \exp (-t) \sinh x \sinh y, \phi(x, y)=$ $\sinh x \sinh y, \psi(x, y)=-\sinh x \sinh y$ in $\Omega ; \phi_{1}(y, t)=$ $0 ; \phi_{2}(y, t)=\exp (-t) \sinh (1) \sinh y$ for $0 \leq y \leq 1$ and $\psi_{3}(x, t)=0 ; \psi_{4}(x, t)=\exp (-t) \sinh x \sinh (1)$ for $0 \leq x \leq 1$. The exact solution [7] is given by

$$
u(x, y, t)=\exp (-t) \sinh x \sinh y .
$$

The solutions are computed for $\alpha=10, \beta=5, \alpha=10, \beta=0$ with parameters $\Delta t=0.01,0.001, h=0.1,0.05$ and $p=1$. The $L_{2}, L_{\infty}$ errors and CPU time for different time levels $t \leq 10$ are compared with the error norms by Mittal and Bhatia [9] taking $\triangle t=0.01, h=0.1$ and are reported in Table 2. In Table 3, the computed results are compared with Mittal and Bhatia [9] and Jiwari et al. [7] for $\triangle t=0.001$ and $h=0.05$. The findings from the above tables confirms that the proposed results are better than [7, 9]. The CPU time is slightly more than [9] due to selection of SSPRK54 algorithm instead of SSP-RK43 algorithm, for time integration. The surface plots of numerical at $t=1,2,3$ with $\Delta t=0.001$ and $h=.05$ are depicted in Fig. 2.

\section{Numerical experiments and discussion}

This section deals with the main goal of the paper, the computation of numerical solutions of 2D telegraph equation using mExp-DQM with SSP-RK54 algorithm. The accuracy and the efficiency of this method is measured in terms of various error norms $\left(L_{2}\right.$, relative error $\left.\left(R_{e}\right), L_{\infty}\right)$ for six ex- 
Table 1: Rate of convergence (ROC) for Example 5.1, Example 5.2 and Example 5.6 with $N_{x}=N_{y}=N$ and $p=1$

\begin{tabular}{|c|c|c|c|c|c|c|c|c|c|c|c|c|}
\hline \multicolumn{13}{|c|}{ Example 5.1 with $\alpha=10, \beta=5, \Delta t=0.01$} \\
\hline \multirow[t]{2}{*}{$N$} & \multicolumn{2}{|l|}{$t=0.5$} & \multicolumn{2}{|l|}{$t=1$} & \multicolumn{2}{|l|}{$t=2$} & \multicolumn{2}{|l|}{$t=3$} & \multicolumn{2}{|l|}{$t=5$} & & \\
\hline & $L_{2}$ & ROC & $L_{2}$ & $R O C$ & $L_{2}$ & $R O C$ & $L_{2}$ & $R O C$ & $L_{2}$ & $R O C$ & & \\
\hline 6 & $2.75 \mathrm{E}-05$ & & $2.15 \mathrm{E}-05$ & & $8.90 \mathrm{E}-06$ & & $3.31 \mathrm{E}-06$ & & $4.51 \mathrm{E}-07$ & & & \\
\hline 11 & $6.90 \mathrm{E}-06$ & 2.28 & $5.35 \mathrm{E}-06$ & 2.30 & $2.23 \mathrm{E}-06$ & 2.28 & 8.34E-07 & 2.28 & $1.14 \mathrm{E}-07$ & 2.28 & & \\
\hline 16 & $3.29 \mathrm{E}-06$ & 1.98 & $2.66 \mathrm{E}-06$ & 1.87 & $1.13 \mathrm{E}-06$ & 1.82 & 4.24E-07 & 1.81 & $5.78 \mathrm{E}-08$ & 1.80 & & \\
\hline 21 & $2.10 \mathrm{E}-06$ & 1.65 & $1.75 \mathrm{E}-06$ & 1.54 & $7.54 \mathrm{E}-07$ & 1.50 & $2.83 \mathrm{E}-07$ & 1.49 & $3.86 \mathrm{E}-08$ & 1.48 & & \\
\hline \multicolumn{13}{|c|}{ Example 5.2 with $\alpha=\beta=1, \triangle t=0.01$} \\
\hline$N$ & $t=0.5$ & & $t=1$ & & $t=3$ & & $t=5$ & & $t=7$ & & 10.0 & \\
\hline 6 & $8.31 \mathrm{E}-04$ & & $6.22 \mathrm{E}-04$ & & $6.79 \mathrm{E}-05$ & & $6.83 \mathrm{E}-06$ & & $6.41 \mathrm{E}-07$ & & $6.14 \mathrm{E}-08$ & \\
\hline 11 & $4.88 \mathrm{E}-04$ & 0.88 & $3.98 \mathrm{E}-04$ & 0.74 & 4.06E-05 & 0.85 & 4.11E-06 & 0.84 & 4.67E-07 & 0.52 & $3.87 \mathrm{E}-08$ & 0.76 \\
\hline 16 & $1.96 \mathrm{E}-04$ & 2.43 & $1.55 \mathrm{E}-04$ & 2.51 & $1.65 \mathrm{E}-05$ & 2.40 & $1.83 \mathrm{E}-06$ & 2.15 & $2.10 \mathrm{E}-07$ & 2.14 & $1.46 \mathrm{E}-08$ & 2.60 \\
\hline 21 & $1.02 \mathrm{E}-04$ & 2.41 & $7.71 \mathrm{E}-05$ & 2.57 & $8.55 \mathrm{E}-06$ & 2.42 & $1.01 \mathrm{E}-06$ & 2.20 & 1.16E-07 & 2.19 & 7.07E-09 & 2.67 \\
\hline \multicolumn{13}{|c|}{ Example 5.6 with $\alpha=\beta=1, \Delta t=0.001$} \\
\hline $\bar{N}$ & $t=0.5$ & & $t=1$ & & $t=2$ & & $t=3$ & & $t=4$ & & 5 & \\
\hline 6 & $1.40 \mathrm{E}-03$ & & $2.28 \mathrm{E}-03$ & & 4.57E-03 & & $5.51 \mathrm{E}-03$ & & $6.39 \mathrm{E}-03$ & & $7.12 \mathrm{E}-03$ & \\
\hline 11 & 2.03E-04 & 3.19 & $2.99 \mathrm{E}-04$ & 3.35 & $1.18 \mathrm{E}-04$ & 6.04 & $5.58 \mathrm{E}-05$ & 7.57 & $5.99 \mathrm{E}-05$ & 7.70 & $4.05 \mathrm{E}-05$ & 8.53 \\
\hline 16 & 8.69E-05 & 2.26 & $1.30 \mathrm{E}-04$ & 2.21 & $5.13 \mathrm{E}-05$ & 2.21 & $2.13 \mathrm{E}-05$ & 2.57 & $2.28 \mathrm{E}-05$ & 2.58 & $1.40 \mathrm{E}-05$ & 2.84 \\
\hline 21 & $4.80 \mathrm{E}-05$ & 2.19 & $7.29 \mathrm{E}-05$ & 2.13 & $2.95 \mathrm{E}-05$ & 2.04 & $1.20 \mathrm{E}-05$ & 2.12 & $1.28 \mathrm{E}-05$ & 2.12 & $7.99 \mathrm{E}-06$ & 2.06 \\
\hline
\end{tabular}

Table 2: Comparison of the mExp-DQM solutions of Example 5.1 with $\alpha=10, \beta=5, \triangle t=0.01, h=0.1$ and $p=1$

\begin{tabular}{|c|c|c|c|c|c|c|c|c|}
\hline \multirow[t]{2}{*}{$t$} & \multicolumn{4}{|l|}{ MCB-DQM [9] } & \multicolumn{4}{|l|}{ mExp-DQM } \\
\hline & $L_{2}$ & $L_{\infty}$ & $R_{e}$ & $C P U(s)$ & $L_{2}$ & $L_{\infty}$ & $R_{e}$ & $C P U(s)$ \\
\hline 0.5 & 8.3931E-04 & 3.3019E-03 & $2.8902 \mathrm{E}-03$ & 0.13 & $6.8998 \mathrm{E}-06$ & $1.0168 \mathrm{E}-05$ & $2.8749 \mathrm{E}-04$ & 0.016 \\
\hline 1 & $6.0254 \mathrm{E}-04$ & $2.0597 \mathrm{E}-03$ & $3.4208 \mathrm{E}-03$ & 0.16 & $5.3522 \mathrm{E}-06$ & 7.0133E-06 & 3.6767E-04 & 0.046 \\
\hline 2 & $2.4167 \mathrm{E}-04$ & $7.6531 \mathrm{E}-04$ & $3.7297 \mathrm{E}-03$ & 0.19 & $2.2337 \mathrm{E}-06$ & $2.8534 \mathrm{E}-06$ & 4.1711E-04 & 0.078 \\
\hline 3 & $8.9534 \mathrm{E}-05$ & 2.7920E-04 & 3.7937E-03 & 0.24 & $8.3375 \mathrm{E}-07$ & $1.0585 \mathrm{E}-06$ & 4.2747E-04 & 0.141 \\
\hline 5 & $1.2168 \mathrm{E}-05$ & $3.7800 \mathrm{E}-05$ & $3.8097 \mathrm{E}-03$ & 0.34 & $1.1352 \mathrm{E}-07$ & $1.4389 \mathrm{E}-07$ & 4.3005E-04 & 0.218 \\
\hline
\end{tabular}

Table 3: Comparison of mExp-DQM solutions of Example 5.1 with $\triangle t=0.001, \alpha=10, \beta=0,5, p=1$ and $h=0.05$

\begin{tabular}{|c|c|c|c|c|c|c|c|c|c|c|}
\hline \multirow{2}{*}{$\begin{array}{l}t \\
\beta=5\end{array}$} & \multicolumn{4}{|l|}{ mExp-DQM } & \multicolumn{4}{|l|}{ MCB-DQM [9] } & \multicolumn{2}{|l|}{ PDQM [7] } \\
\hline & $L_{2}$ & $L_{\infty}$ & $R_{e}$ & CPU(s) & $L_{2}$ & $L_{\infty}$ & $R_{e}$ & CPU(s) & $R_{e}$ & CPU(s) \\
\hline 0.5 & $8.1273 \mathrm{E}-07$ & $1.3152 \mathrm{E}-06$ & $6.6847 \mathrm{E}-05$ & 1.279 & $1.0690 \mathrm{E}-04$ & $2.4738 \mathrm{E}-04$ & $1.1088 \mathrm{E}-04$ & 0.47 & $1.1185 \mathrm{E}-04$ & 6 \\
\hline 1 & $5.8429 \mathrm{E}-07$ & $8.3976 \mathrm{E}-07$ & 7.9233E-05 & 2.496 & $1.5293 \mathrm{E}-05$ & $3.3082 \mathrm{E}-04$ & $1.3266 \mathrm{E}-04$ & 1.10 & $1.8051 \mathrm{E}-04$ & 12 \\
\hline 2 & $2.3507 \mathrm{E}-07$ & $3.2200 \mathrm{E}-07$ & 8.6737E-05 & 5.896 & $4.6468 \mathrm{E}-05$ & $1.1380 \mathrm{E}-05$ & $3.1954 \mathrm{E}-04$ & 1.10 & 4.7289E-04 & 25 \\
\hline 3 & $8.8032 \mathrm{E}-08$ & 1.1937E-07 & $8.8297 \mathrm{E}-05$ & 7.488 & $2.1994 \mathrm{E}-05$ & 4.3577E-05 & $1.3024 \mathrm{E}-04$ & 2.80 & $1.2656 \mathrm{E}-04$ & 37 \\
\hline 5 & $1.1979 \mathrm{E}-08$ & $1.6202 \mathrm{E}-08$ & $8.8694 \mathrm{E}-05$ & 12.402 & $2.7151 \mathrm{E}-06$ & $5.4141 \mathrm{E}-06$ & $1.4439 \mathrm{E}-04$ & 4.30 & $9.2770 \mathrm{E}-04$ & 62 \\
\hline \multicolumn{11}{|l|}{$\beta=0$} \\
\hline 0.5 & $7.2898 \mathrm{E}-07$ & $9.0815 \mathrm{E}-07$ & $5.9958 \mathrm{E}-05$ & 1.279 & $9.2959 \mathrm{E}-05$ & $4.2348 \mathrm{E}-04$ & $3.4675 \mathrm{E}-04$ & 0.52 & $1.1198 \mathrm{E}-04$ & 6 \\
\hline 1 & $8.0739 \mathrm{E}-07$ & $1.0270 \mathrm{E}-06$ & $1.0949 \mathrm{E}-04$ & 2.511 & $6.3652 \mathrm{E}-05$ & $2.5838 \mathrm{E}-04$ & 3.9146E-04 & 0.98 & $1.8635 \mathrm{E}-04$ & 12 \\
\hline 2 & $5.7525 \mathrm{E}-07$ & $7.2622 \mathrm{E}-07$ & $2.1226 \mathrm{E}-04$ & 5.007 & $2.5540 \mathrm{E}-05$ & $9.5843 \mathrm{E}-05$ & $4.2739 \mathrm{E}-04$ & 1.80 & $5.1797 \mathrm{E}-04$ & 25 \\
\hline 3 & $3.1155 \mathrm{E}-07$ & $3.9340 \mathrm{E}-07$ & $3.1248 \mathrm{E}-04$ & 7.394 & $9.9234 \mathrm{E}-06$ & $3.5340 \mathrm{E}-05$ & $4.5140 \mathrm{E}-04$ & 2.20 & $1.4412 \mathrm{E}-04$ & 37 \\
\hline 5 & 6.7799E-08 & $8.5767 \mathrm{E}-08$ & $5.0198 \mathrm{E}-04$ & 12.470 & $1.5116 \mathrm{E}-06$ & 4.8043E-06 & $5.0758 \mathrm{E}-04$ & 4.50 & $1.0883 \mathrm{E}-04$ & 62 \\
\hline
\end{tabular}


Table 4: Comparison of the mExp-DQM solutions of Example 5.2 with $h=0.1, \triangle=0.01, \alpha=1, \beta=1, p=1$

\begin{tabular}{|c|c|c|c|c|c|c|}
\hline \multirow[t]{2}{*}{$t$} & \multicolumn{3}{|l|}{ mExp-DQM } & \multicolumn{3}{|l|}{ MCB-DQM [9] } \\
\hline & $L_{2}$ & $L_{\infty}$ & $\mathrm{CPU}(\mathrm{s})$ & $L_{2}$ & $L_{\infty}$ & CPU(s) \\
\hline 1 & 3.9796E-04 & $6.7076 \mathrm{E}-04$ & 0.031 & $1.4441 \mathrm{E}-02$ & 2.9996E-02 & 0.03 \\
\hline 2 & 4.5099E-05 & $1.1091 \mathrm{E}-04$ & 0.063 & $1.3898 \mathrm{E}-03$ & $3.9711 \mathrm{E}-03$ & 0.05 \\
\hline 3 & 4.0589E-05 & $7.4545 \mathrm{E}-05$ & 0.109 & $1.3018 \mathrm{E}-03$ & $2.2178 \mathrm{E}-03$ & 0.08 \\
\hline 5 & $4.1078 \mathrm{E}-06$ & $8.6460 \mathrm{E}-06$ & 0.187 & $1.1112 \mathrm{E}-04$ & $2.0618 \mathrm{E}-04$ & 0.11 \\
\hline 7 & 4.6749E-07 & $1.0452 \mathrm{E}-06$ & 0.234 & $1.3695 \mathrm{E}-05$ & $3.0052 \mathrm{E}-05$ & 0.14 \\
\hline 10 & 3.8692E-08 & 7.0454E-08 & 0.312 & $1.4408 \mathrm{E}-06$ & $2.5354 \mathrm{E}-06$ & 0.19 \\
\hline
\end{tabular}

Table 5: Comparison of the mExp-DQM solutions of Example 5.2 with $h=.05, \triangle=0.001, \alpha=\beta=1, p=1$

\begin{tabular}{|c|c|c|c|c|c|c|}
\hline \multirow[t]{2}{*}{$t$} & \multicolumn{3}{|c|}{ mExp-DQM } & \multicolumn{3}{|l|}{ MCB-DQM [9] } \\
\hline & $L_{2}$ & $L_{\infty}$ & CPU(s) & $L_{2}$ & $L_{\infty}$ & CPU(s) \\
\hline 0.5 & $1.28 \mathrm{E}-04$ & 2.67E-04 & 1.045 & $3.4808 \mathrm{E}-03$ & $9.5129 \mathrm{E}-03$ & 0.50 \\
\hline 1 & $1.05 \mathrm{E}-04$ & $1.82 \mathrm{E}-04$ & 2.074 & $3.2351 \mathrm{E}-03$ & $7.4749 \mathrm{E}-03$ & 0.70 \\
\hline 2 & $1.04 \mathrm{E}-05$ & $3.07 \mathrm{E}-05$ & 4.181 & $2.8518 \mathrm{E}-04$ & $1.0361 \mathrm{E}-03$ & 1.30 \\
\hline 3 & $1.09 \mathrm{E}-05$ & $2.05 \mathrm{E}-05$ & 6.255 & $3.1028 \mathrm{E}-04$ & $5.7859 \mathrm{E}-04$ & 1.90 \\
\hline 5 & $1.03 \mathrm{E}-06$ & $2.40 \mathrm{E}-06$ & 10.358 & $2.4495 \mathrm{E}-05$ & $6.7234 \mathrm{E}-05$ & 3.30 \\
\hline 7 & $1.03 \mathrm{E}-07$ & $2.59 \mathrm{E}-07$ & 14.446 & $2.5376 \mathrm{E}-06$ & $8.2203 \mathrm{E}-06$ & 3.90 \\
\hline 10 & $1.18 \mathrm{E}-08$ & $2.18 \mathrm{E}-08$ & 20.498 & $3.6505 \mathrm{E}-06$ & 8.5897E-06 & 5.20 \\
\hline
\end{tabular}

Table 6: Comparison of the mExp-DQM solutions of Example 5.3 with $\triangle t=0.01$ and $h=0.1, p=1$

\begin{tabular}{|c|c|c|c|c|c|c|c|c|}
\hline \multirow[t]{2}{*}{$t$} & \multicolumn{4}{|c|}{ mExp-DQM } & \multicolumn{4}{|c|}{ MCB-DQM [9] } \\
\hline & $L_{2}$ & $L_{\infty}$ & $R_{e}$ & $C P U(s)$ & $L_{2}$ & $L_{\infty}$ & $R_{e}$ & $C P U(s)$ \\
\hline 1 & 3.7330E-06 & 4.5492E-06 & $2.7069 \mathrm{E}-04$ & 0.031 & $9.9722 \mathrm{E}-04$ & $2.2746 \mathrm{E}-03$ & $5.9762 \mathrm{E}-03$ & 0.08 \\
\hline 2 & 4.4842E-06 & 5.6294E-06 & 4.2217E-04 & 0.062 & $1.0926 \mathrm{E}-03$ & $2.8706 \mathrm{E}-03$ & 8.5019E-03 & 0.11 \\
\hline 3 & $3.7742 \mathrm{E}-06$ & $6.3374 \mathrm{E}-06$ & $1.4916 \mathrm{E}-04$ & 0.109 & $2.2877 \mathrm{E}-04$ & $6.0818 \mathrm{E}-04$ & $7.4720 \mathrm{E}-04$ & 0.14 \\
\hline 5 & $4.4186 \mathrm{E}-06$ & $5.3912 \mathrm{E}-06$ & $5.9036 \mathrm{E}-04$ & 0.203 & $1.1562 \mathrm{E}-03$ & $2.9942 \mathrm{E}-03$ & $1.2767 \mathrm{E}-03$ & 0.20 \\
\hline 7 & $3.2109 \mathrm{E}-06$ & $3.7239 \mathrm{E}-06$ & $1.6834 \mathrm{E}-04$ & 0.312 & 7.2867E-04 & $1.8781 \mathrm{E}-03$ & $3.1572 \mathrm{E}-03$ & 0.26 \\
\hline 10 & 3.1806E-06 & $3.7506 \mathrm{E}-06$ & $1.4949 \mathrm{E}-04$ & 0.374 & $5.8889 \mathrm{E}-04$ & $1.5158 \mathrm{E}-03$ & $2.2874 \mathrm{E}-03$ & 0.34 \\
\hline
\end{tabular}

Table 7: Comparison of the mExp-DQM solutions of Example 5.3 with $\triangle t=0.001 ; h=0.05$ and $p=1,0.15$

\begin{tabular}{|c|c|c|c|c|c|c|c|c|c|c|c|c|}
\hline \multirow[t]{2}{*}{$t$} & \multicolumn{4}{|c|}{ mExp-DQM $(p=1)$} & \multicolumn{4}{|c|}{$m \operatorname{Exp}-D Q M(p=0.15)$} & \multicolumn{4}{|l|}{ MCB-DQM [9] } \\
\hline & $L_{2}$ & $L_{\infty}$ & $R_{e}$ & CPU(s) & $L_{2}$ & $L_{\infty}$ & $R_{e}$ & CPU (s) & $L_{2}$ & $L_{\infty}$ & $R_{e}$ & CPU(s) \\
\hline 1 & $3.5715 \mathrm{E}-07$ & $5.8718 \mathrm{E}-07$ & $5.0162 \mathrm{E}-05$ & 2.26 & $3.5729 \mathrm{E}-07$ & $5.8736 \mathrm{E}-07$ & $5.0182 \mathrm{E}-05$ & 2.26 & $9.8870 \mathrm{E}-05$ & 2.4964E-04 & $6.2977 \mathrm{E}-04$ & 0.78 \\
\hline 2 & 4.4969E-07 & $6.7211 \mathrm{E}-07$ & $8.1823 \mathrm{E}-05$ & 4.52 & 4.4977E-07 & $6.7225 \mathrm{E}-07$ & $8.1838 \mathrm{E}-05$ & 4.52 & $1.2148 \mathrm{E}-04$ & $3.2296 \mathrm{E}-04$ & $1.0025 \mathrm{E}-03$ & 1.30 \\
\hline 3 & $7.8128 \mathrm{E}-07$ & $1.2228 \mathrm{E}-06$ & $5.9879 \mathrm{E}-05$ & 6.79 & $7.8151 \mathrm{E}-07$ & $1.2231 \mathrm{E}-06$ & 5.9897E-05 & 6.79 & 3.7627E-05 & $9.9310 \mathrm{E}-05$ & $1.3078 \mathrm{E}-04$ & 1.70 \\
\hline 5 & 3.6743E-07 & 4.4790E-07 & 9.8297E-05 & 11.17 & $3.6749 \mathrm{E}-07$ & 4.4797E-07 & $9.8311 \mathrm{E}-05$ & 11.17 & $1.2762 \mathrm{E}-04$ & 3.3205E-04 & $1.5411 \mathrm{E}-03$ & 3.00 \\
\hline 7 & $5.0400 \mathrm{E}-07$ & $8.8032 \mathrm{E}-07$ & $5.0732 \mathrm{E}-05$ & 15.81 & $5.0417 \mathrm{E}-07$ & $8.8056 \mathrm{E}-07$ & $5.0749 \mathrm{E}-05$ & 15.81 & $6.7672 \mathrm{E}-05$ & $1.7679 \mathrm{E}-04$ & $3.0892 \mathrm{E}-04$ & 3.30 \\
\hline 10 & $5.7992 \mathrm{E}-07$ & $9.9151 \mathrm{E}-07$ & $5.2483 \mathrm{E}-05$ & 22.60 & $5.8011 \mathrm{E}-07$ & $9.9178 \mathrm{E}-07$ & $5.2500 \mathrm{E}-05$ & 22.60 & $5.1764 \mathrm{E}-05$ & $1.3521 \mathrm{E}-04$ & $2.1245 \mathrm{E}-04$ & 5.20 \\
\hline
\end{tabular}


Table 8: Comparison of mExp-DQM solutions of Example 5.4 with $\triangle t=0.001, \alpha=10,50, \beta=5$ and $h=0.05$

\begin{tabular}{|c|c|c|c|c|c|c|c|c|c|}
\hline \multirow{2}{*}{$\begin{array}{l}t \\
\alpha=10\end{array}$} & \multicolumn{6}{|l|}{ mExp-DQM } & \multicolumn{3}{|c|}{ MCB-DQM [9] } \\
\hline & $L_{2}: p=0.015$ & $L_{\infty}: p=0.015$ & CPU(s) & $L_{2}: p=1$ & $L_{\infty}: p=1$ & CPU(s) & $L_{2}$ & $L_{\infty}$ & CPU(s) \\
\hline 0.5 & $2.0862 \mathrm{E}-06$ & $2.8531 \mathrm{E}-06$ & 1.294 & $2.0861 \mathrm{E}-06$ & $2.8527 \mathrm{E}-06$ & 1.310 & $1.070 \mathrm{E}-04$ & $3.756 \mathrm{E}-04$ & 0.57 \\
\hline 1 & $2.5046 \mathrm{E}-06$ & $3.2481 \mathrm{E}-06$ & 2.62 & $2.5045 \mathrm{E}-06$ & $3.2479 \mathrm{E}-06$ & 2.608 & $1.717 \mathrm{E}-04$ & $5.640 \mathrm{E}-04$ & 0.92 \\
\hline 2 & $1.3896 \mathrm{E}-06$ & $1.7942 \mathrm{E}-06$ & 6.115 & 1.3896E-06 & $1.7942 \mathrm{E}-06$ & 5.179 & $1.647 \mathrm{E}-04$ & $5.130 \mathrm{E}-04$ & 1.20 \\
\hline 3 & $1.4008 \mathrm{E}-06$ & $2.2256 \mathrm{E}-06$ & 7.722 & $1.4006 \mathrm{E}-06$ & $2.2252 \mathrm{E}-06$ & 7.722 & $8.986 \mathrm{E}-06$ & $1.956 \mathrm{E}-05$ & 2.30 \\
\hline 5 & $1.6566 \mathrm{E}-06$ & $2.1478 \mathrm{E}-06$ & 12.885 & $1.6566 \mathrm{E}-06$ & $2.1478 \mathrm{E}-06$ & 12.901 & $1.774 \mathrm{E}-04$ & $5.563 \mathrm{E}-04$ & 4.10 \\
\hline 7 & $2.5344 \mathrm{E}-06$ & $3.2884 \mathrm{E}-06$ & 18.142 & $2.5342 \mathrm{E}-06$ & $3.2882 \mathrm{E}-06$ & 18.008 & $1.420 \mathrm{E}-04$ & 4.723E-04 & 5.40 \\
\hline $\begin{array}{l}10 \\
\alpha=50\end{array}$ & $1.8983 \mathrm{E}-06$ & 2.4641E-06 & 25.631 & $1.8983 \mathrm{E}-06$ & $2.4640 \mathrm{E}-06$ & 25.646 & $1.224 \mathrm{E}-04$ & $4.122 \mathrm{E}-04$ & 7.40 \\
\hline 0.5 & $2.2128 \mathrm{E}-06$ & $3.2835 \mathrm{E}-06$ & 1.544 & 2.2127E-06 & $3.2833 \mathrm{E}-06$ & 1.294 & $9.880 \mathrm{E}-05$ & $3.696 \mathrm{E}-04$ & 0.57 \\
\hline 1 & $3.2434 \mathrm{E}-06$ & 4.4892E-06 & 2.574 & $3.2433 \mathrm{E}-06$ & 4.4891E-06 & 2.605 & $1.677 \mathrm{E}-04$ & $5.687 \mathrm{E}-04$ & 0.94 \\
\hline 2 & $2.4069 \mathrm{E}-06$ & $3.2575 \mathrm{E}-06$ & 5.194 & $2.4069 \mathrm{E}-06$ & $3.2575 \mathrm{E}-06$ & 5.179 & $1.711 \mathrm{E}-04$ & $5.257 \mathrm{E}-04$ & 1.40 \\
\hline 3 & $1.6269 \mathrm{E}-06$ & 2.8366E-06 & 7.800 & 1.6267E-06 & $2.8362 \mathrm{E}-06$ & 7.769 & $1.741 \mathrm{E}-05$ & $4.346 \mathrm{E}-05$ & 2.50 \\
\hline 5 & $3.1532 \mathrm{E}-06$ & 4.2934E-06 & 13.182 & $3.1531 \mathrm{E}-06$ & 4.2933E-06 & 13.104 & $1.842 \mathrm{E}-04$ & $5.694 \mathrm{E}-04$ & 4.10 \\
\hline 7 & $3.5801 \mathrm{E}-06$ & $5.1314 \mathrm{E}-06$ & 18.19 & 3.5799E-06 & $5.1312 \mathrm{E}-06$ & 18.018 & $1.376 \mathrm{E}-04$ & $4.759 \mathrm{E}-04$ & 6.00 \\
\hline 10 & $3.3621 \mathrm{E}-06$ & $4.8638 \mathrm{E}-06$ & 20.748 & $3.3620 \mathrm{E}-06$ & 4.8635E-06 & 26.198 & $1.1691 \mathrm{E}-04$ & 4.1396E-04 & 8.80 \\
\hline
\end{tabular}

Table 9: Comparison of the mExp-DQM solutions of Example 5.5 with $h=0.1, \triangle=0.01, \alpha=\beta=1$

\begin{tabular}{|c|c|c|c|c|c|c|c|c|}
\hline \multirow[t]{2}{*}{$t$} & \multicolumn{5}{|c|}{$\mathrm{mExp}-\mathrm{DQM}(p=0.5,1)$} & \multicolumn{3}{|l|}{ MCB-DQM [9] } \\
\hline & $L_{2}: p=1$ & $L_{\infty}: p=1$ & $L_{2}: p=0.5$ & $L_{\infty}: p=0.5$ & CPU(s) & $L_{2}$ & $L_{\infty}$ & $\mathrm{CPU}(\mathrm{s})$ \\
\hline 1 & $5.7365 \mathrm{E}-04$ & $7.1586 \mathrm{E}-04$ & $5.7365 \mathrm{E}-04$ & 7.1591E-04 & 0.05 & $1.6144 \mathrm{E}-03$ & 3.6006E-03 & 0.07 \\
\hline 2 & $1.7371 \mathrm{E}-04$ & $2.2392 \mathrm{E}-04$ & $1.7372 \mathrm{E}-04$ & $2.2396 \mathrm{E}-04$ & 0.11 & $2.6345 \mathrm{E}-03$ & $5.7068 \mathrm{E}-03$ & 0.09 \\
\hline 3 & $1.9296 \mathrm{E}-05$ & $2.1468 \mathrm{E}-05$ & $1.9298 \mathrm{E}-05$ & $2.1476 \mathrm{E}-05$ & 0.14 & $5.3845 \mathrm{E}-04$ & $1.2479 \mathrm{E}-03$ & 0.11 \\
\hline 5 & $6.4893 \mathrm{E}-06$ & $8.5658 \mathrm{E}-06$ & $6.4900 \mathrm{E}-06$ & $8.5675 \mathrm{E}-06$ & 0.25 & $1.2418 \mathrm{E}-04$ & $2.1003 \mathrm{E}-04$ & 0.15 \\
\hline 7 & $1.3028 \mathrm{E}-06$ & $1.6270 \mathrm{E}-06$ & $1.3028 \mathrm{E}-06$ & $1.6272 \mathrm{E}-06$ & 0.33 & $1.3653 \mathrm{E}-05$ & $2.6261 \mathrm{E}-05$ & 0.12 \\
\hline 10 & $5.8266 \mathrm{E}-08$ & 7.3567E-08 & $5.8266 \mathrm{E}-08$ & 7.3573E-08 & 0.45 & $7.5592 \mathrm{E}-06$ & $1.4083 \mathrm{E}-06$ & 0.20 \\
\hline
\end{tabular}

Table 10: Comparison of the mExp-DQM solutions of Example 5.5 with $h=0.05, \triangle=0.001, \alpha=\beta=1, p=0.5,1$

\begin{tabular}{|c|c|c|c|c|c|c|c|c|}
\hline \multirow[t]{2}{*}{$t$} & \multicolumn{5}{|c|}{$m \operatorname{Exp}-\mathrm{DDQM}(\mathrm{p}=0.5,1)$} & \multicolumn{3}{|l|}{ MCB-DQM [9] } \\
\hline & $L_{2}: p=1$ & $L_{\infty}: p=1$ & $L_{2}: p=0.5$ & $L_{\infty}: p=0.5$ & $\mathrm{CPU}(\mathrm{s})$ & $L_{2}$ & $L_{\infty}$ & $\mathrm{CPU}(\mathrm{s})$ \\
\hline 0.5 & $3.2617 \mathrm{E}-05$ & $4.6301 \mathrm{E}-05$ & $3.2617 \mathrm{E}-05$ & 4.6306E-05 & 1.33 & 3.5833E-04 & $9.5129 \mathrm{E}-04$ & 0.3 \\
\hline 1 & $5.5100 \mathrm{E}-05$ & $7.2237 \mathrm{E}-05$ & $5.5100 \mathrm{E}-05$ & $7.2239 \mathrm{E}-05$ & 2.54 & $3.2351 \mathrm{E}-04$ & $7.4749 \mathrm{E}-04$ & 0.7 \\
\hline 2 & $1.5539 \mathrm{E}-05$ & 2.1379E-05 & $1.5539 \mathrm{E}-05$ & $2.1380 \mathrm{E}-05$ & 5.09 & $2.8518 \mathrm{E}-05$ & $1.0361 \mathrm{E}-04$ & 1.3 \\
\hline 3 & $8.3598 \mathrm{E}-07$ & $1.1501 \mathrm{E}-06$ & $8.3602 \mathrm{E}-07$ & $1.1504 \mathrm{E}-06$ & 7.61 & $3.1028 \mathrm{E}-05$ & $5.7859 \mathrm{E}-04$ & 1.7 \\
\hline 5 & $5.1811 \mathrm{E}-07$ & $7.4769 \mathrm{E}-07$ & $5.1812 \mathrm{E}-07$ & $7.4772 \mathrm{E}-07$ & 12.81 & $2.4495 \mathrm{E}-06$ & $6.7234 \mathrm{E}-05$ & 2.9 \\
\hline 7 & $1.5582 \mathrm{E}-07$ & $1.9983 \mathrm{E}-07$ & $1.5582 \mathrm{E}-07$ & $1.9983 \mathrm{E}-07$ & 17.78 & $2.5376 \mathrm{E}-07$ & $8.2203 \mathrm{E}-07$ & 4.1 \\
\hline 10 & 7.1281E-09 & 9.0990E-09 & 7.1281E-09 & $9.0991 \mathrm{E}-09$ & 25.80 & $3.6505 \mathrm{E}-09$ & 8.5897E-08 & 5.4 \\
\hline
\end{tabular}

Table 11: Comparison of the mExp-DQM solutions of Example 5.6 with $\alpha=\beta=1, \triangle t=0.001, p=1$ and $h=0.05$

\begin{tabular}{|c|c|c|c|c|c|c|c|c|c|c|c|c|}
\hline \multirow[t]{2}{*}{$t$} & \multicolumn{4}{|l|}{ mExp-DQM } & \multicolumn{4}{|l|}{ MCB-DQM [9] } & \multicolumn{4}{|c|}{ Dehghan and Ghesmati [2] } \\
\hline & $L_{2}$ & $L_{\infty}$ & $R_{e}$ & CPU (s) & $L_{2}$ & $L_{\infty}$ & $R_{e}$ & CPU (s) & $R_{e}: \mathrm{MLWS}$ & CPU (s) & $R_{e}: \mathrm{MLPG}$ & CPU (s) \\
\hline 0.5 & $4.795 \mathrm{E}-05$ & $9.727 \mathrm{E}-05$ & $1.097 \mathrm{E}-03$ & 1.05 & $.069 \mathrm{E}-03$ & $2.474 \mathrm{E}-03$ & $1.109 \mathrm{E}-03$ & 0.5 & $7.939 \mathrm{E}-05$ & 9.2 & $9.991 \mathrm{E}-05$ & 21.0 \\
\hline 1 & $7.290 \mathrm{E}-05$ & $1.081 \mathrm{E}-04$ & $1.394 \mathrm{E}-03$ & 2.18 & $.529 \mathrm{E}-03$ & $3.308 \mathrm{E}-03$ & $1.327 \mathrm{E}-03$ & 1.1 & $9.098 \mathrm{E}-05$ & 12.9 & $7.198 \mathrm{E}-05$ & 36.2 \\
\hline 2 & $2.946 \mathrm{E}-05$ & 4.931E-05 & 4.466E-04 & 4.23 & 4.647E-04 & $1.138 \mathrm{E}-03$ & $3.195 \mathrm{E}-04$ & 2.0 & $8.705 \mathrm{E}-04$ & 25.7 & $8.784 \mathrm{E}-05$ & 49.1 \\
\hline 3 & $1.200 \mathrm{E}-05$ & $2.086 \mathrm{E}-05$ & $1.567 \mathrm{E}-04$ & 6.28 & $2.199 \mathrm{E}-04$ & $4.358 \mathrm{E}-04$ & $1.302 \mathrm{E}-04$ & 2.8 & $9.931 \mathrm{E}-04$ & 38.1 & $4.801 \mathrm{E}-04$ & 66.8 \\
\hline 4 & $1.281 \mathrm{E}-05$ & $1.948 \mathrm{E}-05$ & $1.502 \mathrm{E}-04$ & 8.46 & $2.715 \mathrm{E}-04$ & $5.414 \mathrm{E}-04$ & $1.444 \mathrm{E}-05$ & 4.3 & 4.703E-03 & 49.8 & $6.091 \mathrm{E}-04$ & 82.0 \\
\hline 5 & $7.989 \mathrm{E}-06$ & $1.247 \mathrm{E}-05$ & $8.626 \mathrm{E}-05$ & 10.49 & $.720 \mathrm{E}-04$ & $3.481 \mathrm{E}-04$ & $8.423 \mathrm{E}-05$ & 7.0 & $7.302 \mathrm{E}-03$ & 62.0 & $9.498 \mathrm{E}-04$ & 97.3 \\
\hline 10 & $2.738 \mathrm{E}-06$ & 4.198E-06 & $2.314 \mathrm{E}-05$ & 21.00 & $7.729 \mathrm{E}-05$ & $1.404 \mathrm{E}-04$ & $2.962 \mathrm{E}-05$ & 9.6 & & & & \\
\hline
\end{tabular}



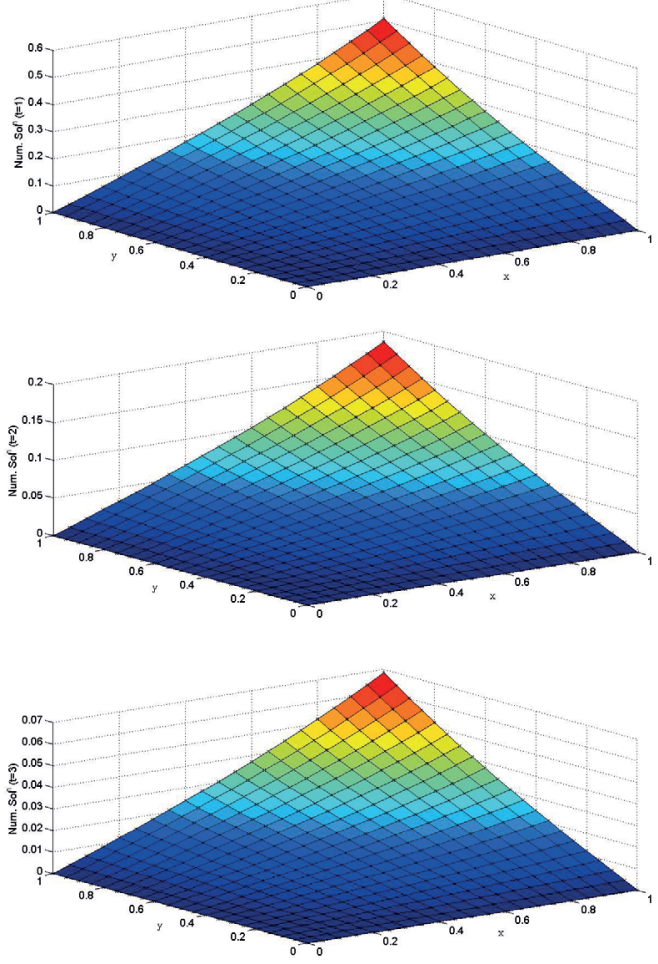

Fig. 2: Plots of numerical solution at different time levels for Example 5.1

Example 5.2. Consider telegraph equation (1) in the region $\Omega$ with $\alpha=\beta=1, f(x, y, t)=-2 \exp (x+y-t), \phi(x, y)=$ $\exp (x+y), \psi(x, y)=-\exp (x+y)$ in $\Omega$ and the mixed boundary conditions $\phi_{1}(y, t)=\exp (y-t), \phi_{2}(y, t)=$ $\exp (1+y-t)$ for $0 \leq y \leq 1$ and $\psi_{3}(x, t)=$ $\exp (x-t), \phi_{4}(x, t)=\exp (1+x-t)$ for $0 \leq x \leq 1$. The exact solution [4] is given by

$$
u(x, y, t)=\exp (x+y-t)
$$

The computed results and CPU time are compared with the results by Mittal and Bhatia [9] for different space step size $h=0.1,0.05$ and time step size $\Delta t=0.01,0.001, p=1$ and reported in Table 4 and Table 5. The surface plots of the mExp-DQM solutions at different time levels $t=1,2,4$ is depicted in Fig. 3. The findings show that the proposed results are more accurate than the results by Mittal and Bhatia [9].
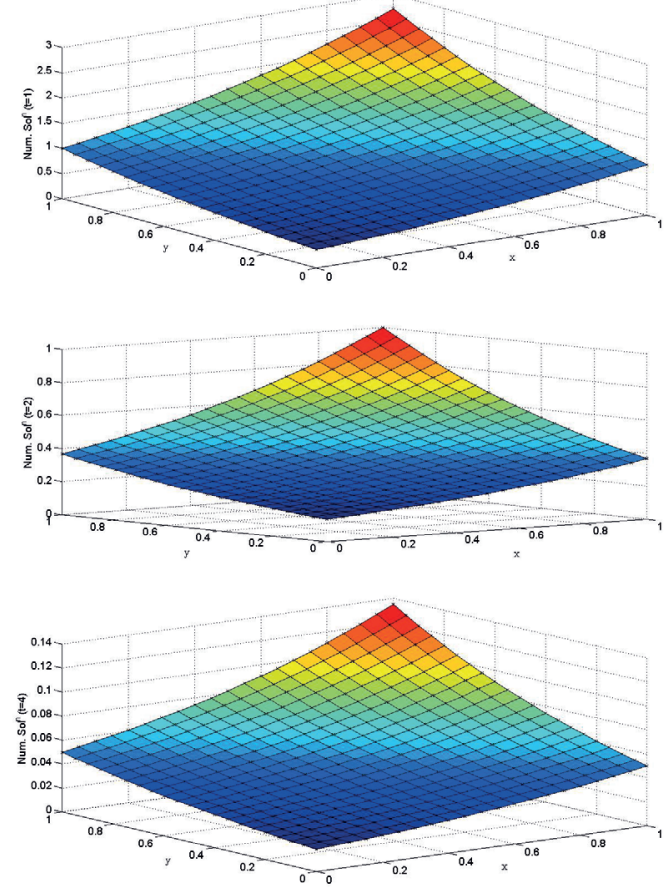

Fig. 3: Plots of mExp-DQM solutions solutions at different time levels for Example 5.2

Example 5.3. Consider telegraph equation (1) in $\Omega$ with $\alpha=\beta=1, f(x, y, t)=2(\cos t-\sin t) \sin x \sin y, \phi(x, y)=$ $\sin x \cdot \sin y ; \psi(x, y)=0$ and the Dirichlet boundary conditions: $\phi_{1}(y, t)=0, \phi_{2}(y, t)=\cos t \sin (1) \sin y, 0 \leq y \leq$ $1, \phi_{3}(x, t)=0, \phi_{4}(x, t)=\cos t \sin x \sin (1), 0 \leq x \leq 1$.

The exact solution [4] is

$$
u(x, y, t)=\cos t \sin x \sin y
$$

The computed relative error $\left(R_{e}\right), L_{2}, L_{\infty}$ error norms are compared with the recent results of Mittal and Bhatia [9] at different time levels $t \leq 10$, reported in Table 6 and Table 7 with the parameters $\triangle t=0.01, h=0.1, p=1$ and $\triangle t=0.001$ and $h=0.05, p=0.15,1$, respectively. The physical solution behavior at $t=1,2,3$ is depicted in Fig. 4 . The findings shows that the proposed solution are much better than the results by Mittal and Bhatia [9], and are in excellent agreement with the exact solutions. The computation time is slightly more than Mittal and Bhatia [9] for large $t$ due to selection of SSP-RK54 algorithm instead of SSP-RK43 algorithm in time integration. 

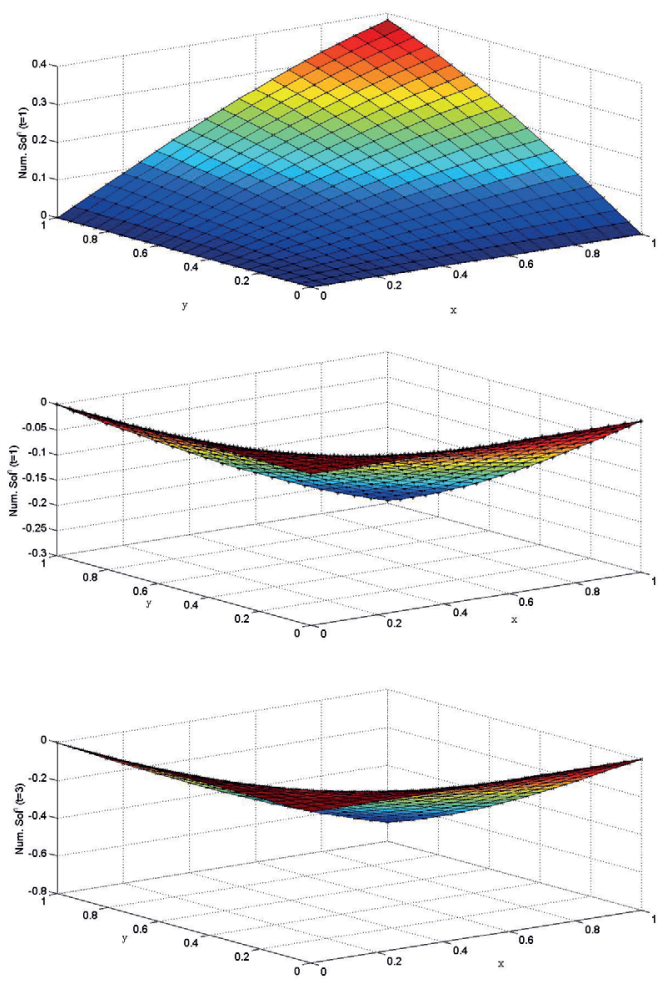

Fig. 4: Plots of mExp-DQM solution solution of Example 5.3

Example 5.4. Consider telegraph equation (1) in the region $\Omega$ with $f(x, y, t)=\left(-3 \cos t+2 \alpha \sin t+\beta^{2} \cos t\right) \sinh x \sinh y$, and $\phi(x, y)=\sinh x \sinh y, \psi(x, y)=0$ in $\Omega$, and $\phi_{1}(y, t)=$ $0, \phi_{2}(y, t)=\cos t \sinh (1) \sinh y$ for $0 \leq y \leq 1$, and $\phi_{3}(x, t)=0, \psi_{4}(x, t)=\cos t \sinh x \sinh (1)$ for $0 \leq x \leq 1$. The exact solution [7] is given by

$$
u(x, y, t)=\cos t \sinh x \sinh y .
$$

The solutions are computed with the parameters $\alpha=$ $10, \beta=5$ and $\alpha=50, \beta=5$ for the time step $\triangle t=0.001$ and $h=0.05, p=0.15,1$. The computed $L_{2}, L_{\infty}$ errors norms and CPU time at different time levels are reported in Table 8. It evident that our results are comparably better than the results by Bhatiya and Mittal[9]. The numerical solutions at $t=1$, 2, 3 has been depicted in Fig. 5 .
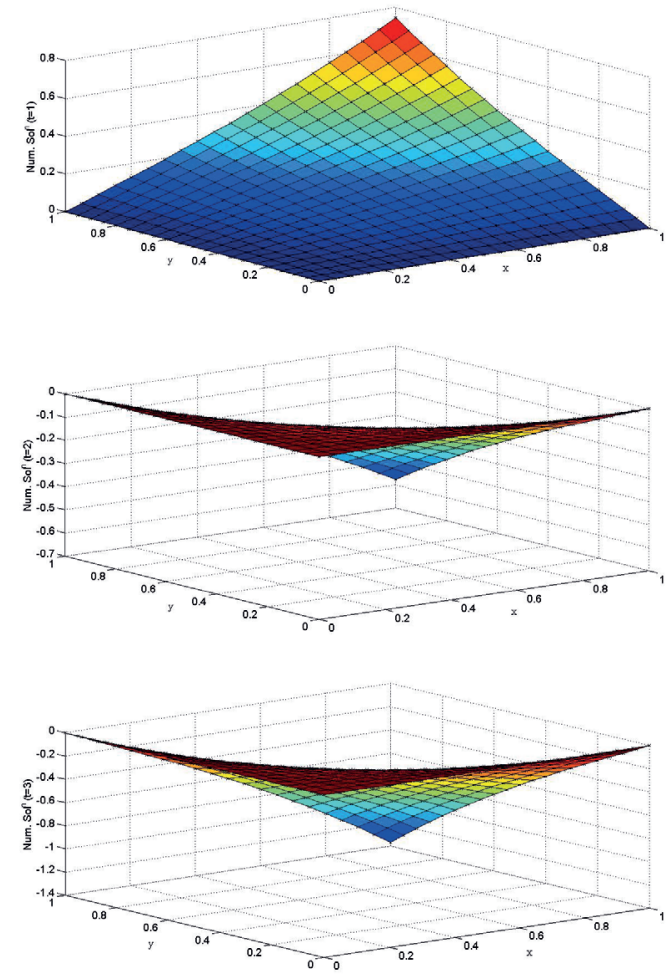

Fig. 5: Plots of numerical solution at different time levels for Example 5.4

Example 5.5. Consider telegraph equation (1) with $\alpha=1, \beta=1, f(x, y, t)=2 \pi^{2} \exp (-t) \sin \pi x \sin \pi y$ in region $\Omega, t>0$ is considered together with $\phi(x, y)=\sin \pi x \sin \pi y, \psi(x, y)=-\sin \pi x \sin \pi y$ in $\Omega$, and the mixed boundary conditions $\psi_{1}(y, t)=$ $\pi \exp (-t) \sin (\pi y), \phi_{2}(y, t)=0$ in $0 \leq y \leq 1$, and $\phi_{3}(x, t)=0, \psi_{4}(x, t)=-\pi \exp (-t) \sin (\pi y)$ in $0 \leq x \leq 1$. The exact solution as in [4] is given by

$$
u(x, y, t)=\exp (-t) \sin (\pi x) \sin (\pi y) .
$$

The solutions are computed in terms of $L_{2}, L_{\infty}$ error norms, for $h=0.1, \Delta t=0.01$ and $h=0.05, \Delta t=0.001$ with $p=0.5,1$ and reported in Table 9 and Table 10. The surface plots of numerical solutions at different time levels $t=0.5,1,2$ are depicted in Fig. 6. The above findings confirms that the proposed mExp-DQM solutions are more accurate than the results by Mittal and Bhatia [9]. 

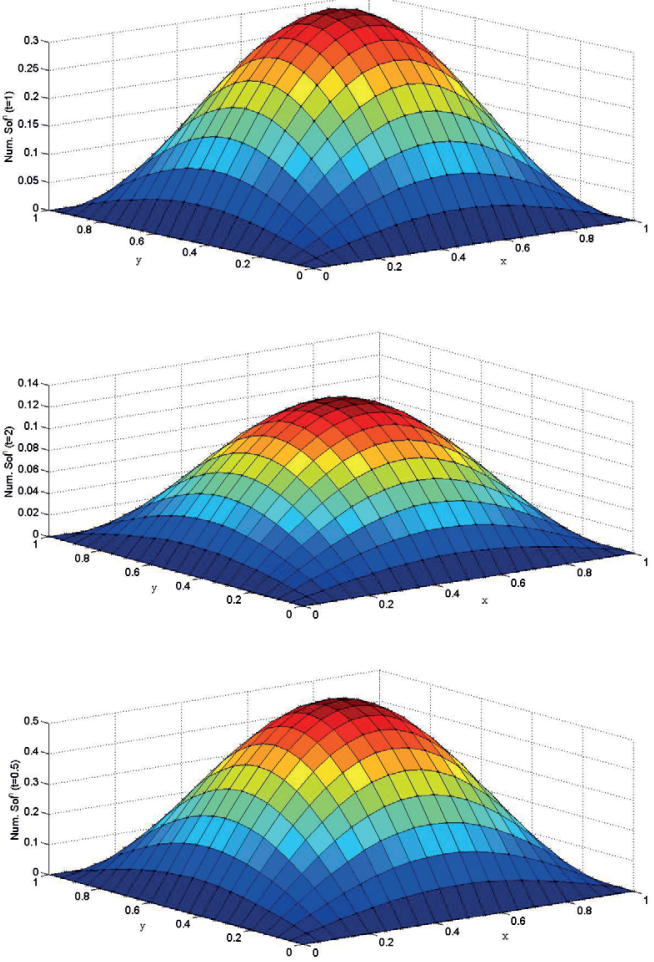

Fig. 6: Plots of numerical solution at different time levels for Example 5.5

Example 5.6. Consider telegraph equation (1) with $\alpha=$ $\beta=1$ is considered together with $\phi(x, y)=\log (1+x+$ $y), \psi(x, y)=\frac{1}{1+x+y}$ in $\Omega$, and the mixed boundary conditions $\phi_{1}(y, t)=\log (1+y+t), \psi_{2}(y, t)=\frac{1}{2+y+t}$ for $0 \leq y \leq 1$ and $\psi_{3}(x, t)=\frac{1}{1+x+t}, \phi_{4}(x, t)=\log (2+x+t)$ for $0 \leq x \leq 1$. The exact solution as given in [4] is:

$$
u(x, y, t)=\log (1+x+y+t)
$$

where the function $f(x, y, t)$ can be extracted from the exact solution.

The solutions are computed for $p=1, \Delta t=0.001, h=$ 0.05 in the region $\Omega$ in terms of $L_{2}, L_{\infty}$ and relative error norms. The computed results are compared with the results by Mittal and Bhatia [9] and Dehghan and Ghesmati [2], reported in Table 11. It is evident from Table 11 that the accuracy of $m E x p-D Q M$ results is much better than the accuracy in the results of [9], and [2] for large t. The surface plots of numerical solutions at different time levels $t=1,2,3$ are depicted in Fig. 7.
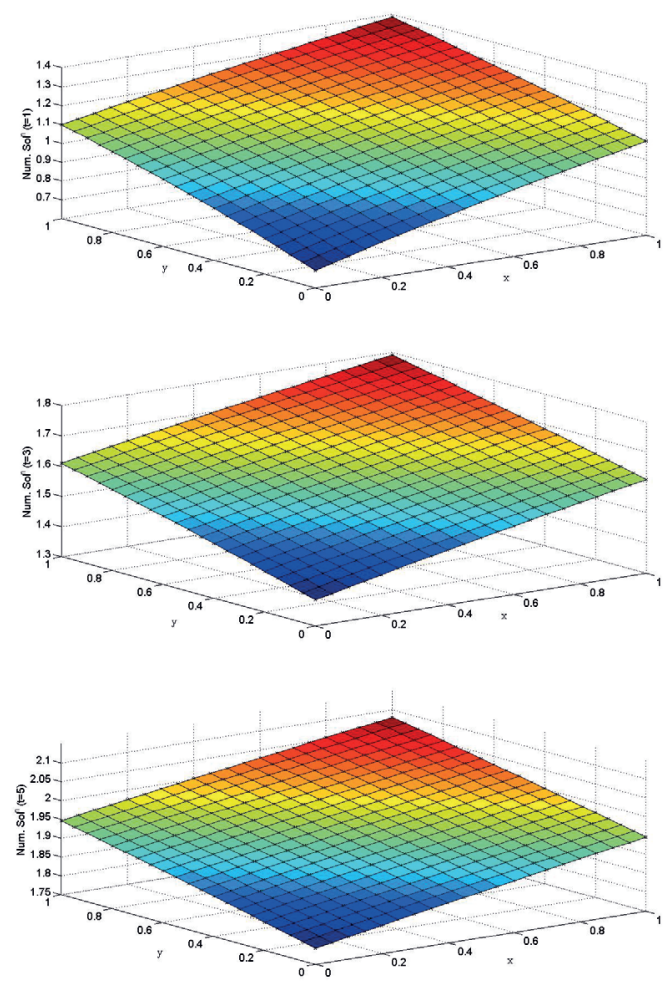

Fig. 7: Plots of numerical solution at different time levels for Example 5.6

\section{Conclusion}

In this paper, a new method "modified exponential cubic B-spline differential quadrature method (mExp-DQM)" has been developed. The mExp-DQM with SSP-RK54 algorithm has been implemented for $(2+1) D$ hyperbolic telegraph equation together with initial conditions and each type (Drichlet, Neumann or mixed type) of boundary conditions. The results are compared with the recent results by Mittal and Bhatia [9] and Jiwari et al. [7]. The findings show that the accuracy of proposed results have excellent agreement with very recent and accurate results reported in $[7,9]$. The CPU time is more than [9], while very less in comparison to [7]. Finally, we conclude that mExp-DQM results with suitable value of free parameter $p$ produces better results than $[7,9]$.

Acknowledgement: The authors would like to thank the anonymous referees for their time, effort, and extensive comments which improve the quality of the presentation of the paper. Pramod Kumar would like to thanks BBA University Lucknow, India for financial assistance to carry out the research work. 


\section{References}

[1] M. Lakestani, B.N. Saray, Numerical solution of telegraph equation using interpolating scaling functions, Comput. Math. Appl. 60 (7) (2010) 1964-1972.

[2] M. Dehghan, A. Ghesmati, Combination of meshless local weak and strong (MLWS) forms to solve the two dimensional hyperbolic telegraph equation, Eng. Anal. Bound. Elem. 34 (4) (2010) 324-336.

[3] D M Pozar, Microwave Engineering, Addison-Wesley, 1990.

[4] M. Dehghan, A. Ghesmati, Solution of the second-order onedimensional hyperbolic telegraph equation by using the dual reciprocity boundary integral equation (DRBIE) method, Eng. Anal. Bound. Elem. 34 (1) (2010) 51-59.

[5] B. Bülbül, M. Sezer, A Taylor matrix method for the solution of a two-dimensional linear hyperbolic equation, Appl. Math. Lett. 24 (10) (2011) 1716-1720.

[6] M. Dehghan, A. Mohebbi, High order implicit collocation method for the solution of two-dimensional linear hyperbolic equation, Numer. Methods Partial Differ. Equ. 25 (1) (2009) 232-243.

[7] R. Jiwari, S. Pandit, R.C. Mittal, A differential quadrature algorithm to solve the two dimensional linear hyperbolic telegraph equation with Dirichlet and Neumann boundary conditions, Appl. Math. Comput. 218 (13) (2012) 7279-7294.

[8] A. Korkmaz, I. Dag, Polynomial based differential quadrature method for numerical solution of nonlinear Burgers' equation, J. Franklin Inst. 348 (10) (2011) 2863- 2875.

[9] R.C. Mittal, R. Bhatia, A numerical study of two dimensional hyperbolic telegraph equation by modified B-spline differential quadrature method, Appl. Math. Comput. 244 (2014) 976-997.

[10] R.K. Mohanty, M.K. Jain, An unconditionally stable alternating direction implicit scheme for the two space dimensional linear hyperbolic equation, Numer. Methods Partial Differ. Equ. 17 (6) (2001) 684-688.

[11] M. Dehghan, R. Salehi, A method based on meshless approach for the numerical solution of the two-space dimensional hyperbolic telegraph equation, Math. Methods Appl. Sci. 35 (10) (2012) 1220-1233.

[12] B.K. Singh, P. Kumar, A novel approach for numerical computation of Burgers equation $(1+1)$ and $(2+1)$ dimension, Alexandria Eng. J. 55 (4) (2016) 3331-3344.

[13] H. Ding, Y. Zhang, A new fourth-order compact finite difference scheme for the two-dimensional second-order hyperbolic equation, J. Comput. Appl. Math. 230 (2) (2009) 626-632.

[14] M. Dehghan, A. Shokri, A meshless method for numerical solution of a linear hyperbolic equation with variable coefficients in two space dimensions, Numer. Methods Partial Differ. Equ 25 (2) (2009) 494-506.

[15] R. Bellman, B.G. Kashef, J. Casti, Differential quadrature: a technique for the rapid solution of nonlinear partial differential equations, J. Comput. Phys. 10 (1972) 40-52.

[16] J.R. Quan, C.T. Chang, New insights in solving distributed system equations by the quadrature method-II, Comput. Chem. Eng. 13 (9) (1989) 1017-1024.

[17] J.R. Quan, C.T. Chang, New insights in solving distributed system equations by the quadrature method-I, Comput. Chem. Eng. 13 (7) (1989) 779-788.
[18] A. Korkmaz, I. Dag, Cubic B-spline differential quadrature methods and stability for Burgers' equation, Eng. Comput. Int. J. Comput. Aided Eng. Software 30 (3) (2013) 320-344.

[19] A. Korkmaz, I. Dag, Numerical simulations of boundary - forced RLW equation with cubic B-spline-based differential quadrature methods, Arab J Sci Eng 38 (2013) 1151-1160.

[20] G. Arora, B.K. Singh, Numerical solution of Burgers' equation with modified cubic B-spline differential quadrature method. Applied Math. Comput. 224 (2013) 166-177.

[21] B. K. Singh, A novel approach for numeric study of 2D biological population model, Cogent Mathematics (2016) 3: 1261527, http://dx.doi.org/10.1080/23311835.2016.1261527.

[22] B. K. Singh, C. Bianca, A new numerical approach for the solutions of partial differential equations in three-dimensional space, Appl. Math. Inf. Sci. 10, No. 5, 1-10 (2016).

[23] B. K. Singh, G. Arora, M. K.Singh, A numerical scheme for the generalized Burgers-Huxley equation, Journal of the Egyptian Mathematical Society 24(4) (2016) 629-637.

[24] A.G. Striz, X. Wang, C.W. Bert, Harmonic differential quadrature method and applications to analysis of structural components, Acta Mech. 111 (1-2)(1995) 85-94.

[25] A. Korkmaz, I. Dag, Shock wave simulations using sinc differential quadrature method, Eng. Comput. Int. J. Comput. Aided Eng. Software 28 (6) (2011) 654-674.

[26] C. Shu, B. E. Richards, Application of generalized differential quadrature to solve two dimensional incompressible navierStokes equations, Int. J. Numer. Meth.Fluids 15 (1992) 791-798.

[27] A. Korkmaz, A.M. Aksoy, I. Dag, Quartic B-spline differential quadrature method, Int. J. Nonlinear Sci. 11 (4) (2011) 403-411.

[28] A. Başhan, S. B. G. Karakoç, T. Geyikli, Approximation of the KdVB equation by the quintic B-spline differential quadrature method. Kuwait J. Sci. 42 (2) (2015) 67-92.

[29] A. Başhan, S. B. G. Karakoç, T. Geyikli, B-spline differential quadrature method for modified Burgers equation. Çankaya Univ. J. Sci. Engg. 12(1) (2015) 113.

[30] A. Korkmaz, I. Dag, Quartic and quintic Bspline methods for advection diffusion equation. Applied Mathematics and Computation 274 (2016) 208-219.

[31] A. Korkmaz, and H. K. Akmaz, Numerical simulations for transport of conservative pollutants. Selcuk J. Appl. Math. 16(1) (2015).

[32] J. R. Spiteri, S. J. Ruuth, A new class of optimal high-order strong stability-preserving time-stepping schemes, SIAM J. Numer.Analysis 40 (2) (2002) 469-491.

[33] Ozlem Ersoy and Idris Dag, Numerical solutions of the reaction diffusion system by using exponential cubic B-spline collocation algorithms, Open Phys. 13(2015)414-427.

[34] B.K. Singh, P. Kumar, A novel aproach for numerical study of two dimensional hyperbolic telegraph equation, Alexandria Eng. J. (2016) http://dx.doi.org/10.1016/j.aej.2016.11.009.

[35] M.K. Jain, Numerical Solution of Differential Equations, 2nd ed., Wiley, New York, NY, 1983.

[36] Ethan J. Kubatko, Benjamin A. Yeager, David I. Ketcheson, Optimal strong-stability-preserving Runge-Kutta time discretizations for discontinuous Galerkin methods, http://www. davidketcheson.info/assets/papers/dg-ssp-stability.pdf.

[37] P. M. Prenter, Splines and Variational Methods, Wiley, New York, 1975. 